\title{
The Comparative Advantage of Cities*
}

\author{
Donald R. Davis ${ }^{\dagger}$ \\ Columbia University and NBER \\ Jonathan I. Dingel ${ }^{\ddagger}$ \\ Columbia University
}

\author{
June 2013 \\ Preliminary and Incomplete
}

\begin{abstract}
What determines the distributions of skills, occupations, and industries across cities? We develop a theory to jointly address these fundamental questions about the spatial organization of economies. Our model incorporates a system of cities, their internal urban structures, and a high-dimensional theory of factor-driven comparative advantage. It predicts that larger cities will be skill abundant and specialize in skillintensive activities according to the monotone likelihood ratio property. We test the model using data on 270 US metropolitan areas, 3 to 9 educational categories, 22 occupations, and 21 manufacturing industries. The results provide support for our theory's predictions.
\end{abstract}

${ }^{*}$ We thank Corinne Low, Joan Monras, Keeyoung Rhee, Bernard Salanie, Daniel Sturm, and attendees of the Columbia international trade colloquium and international economics workshop for helpful comments. We thank Yuxiao Huang and especially Antonio Miscio for research assistance. Dingel acknowledges financial support from the Institute for Humane Studies and the Program for Economic Research at Columbia University.

drdavis@columbia.edu

jid2106@columbia.edu 


\section{Introduction}

The distributions of skills, occupations, and industries vary substantially and systematically across US cities. Figures 1 through 3 illustrate this with three selected examples for each.

- Figure 1 plots the population of three educational attainment categories against total metropolitan area population 11 The left panel plots the data; the right panel plots a locally weighted regression for each category. While each educational category's population rises with metropolitan population, the relative levels also exhibit a systematic relationship with city size. Comparing elasticities, the population with a bachelor's degree rises with city size faster than the population of college dropouts, which in turn rises faster than the population of high-school graduates.

Figure 1: Populations of three educational groups across US metropolitan areas
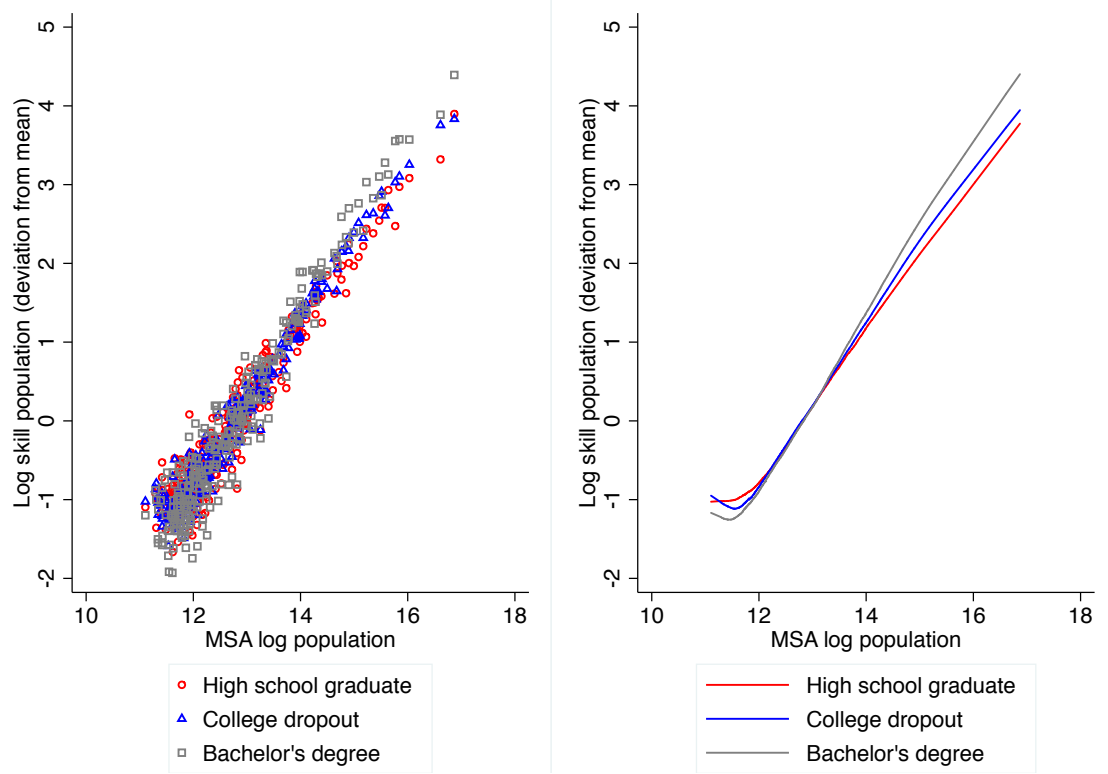

Data source: 2000 Census of Population microdata via IPUMS-USA

- Figure 2 plots metropolitan area employment in three occupational categories 2 Computer and mathematical employment rises with city size faster than office and administrative employment, which in turn rises faster than installation, maintenance and repair employment. These sectors also differ in their employee characteristics. Nationally, the average individual in computer and mathematical occupations has about two more years of schooling than the average individual in office and administrative support and three more years than those in installation, maintenance, and repair.

\footnotetext{
${ }^{1}$ We use the terms cities and metropolitan areas interchangeably, as is customary in the literature. These three educational groups comprise about 70 percent of the employed metropolitan population (see Table 1 ).

${ }^{2}$ The occupations are SOC 49, 43, and 15 in the 2000 Occupational Employment Statistics data.
} 
Figure 2: Employment in three occupations across US metropolitan areas
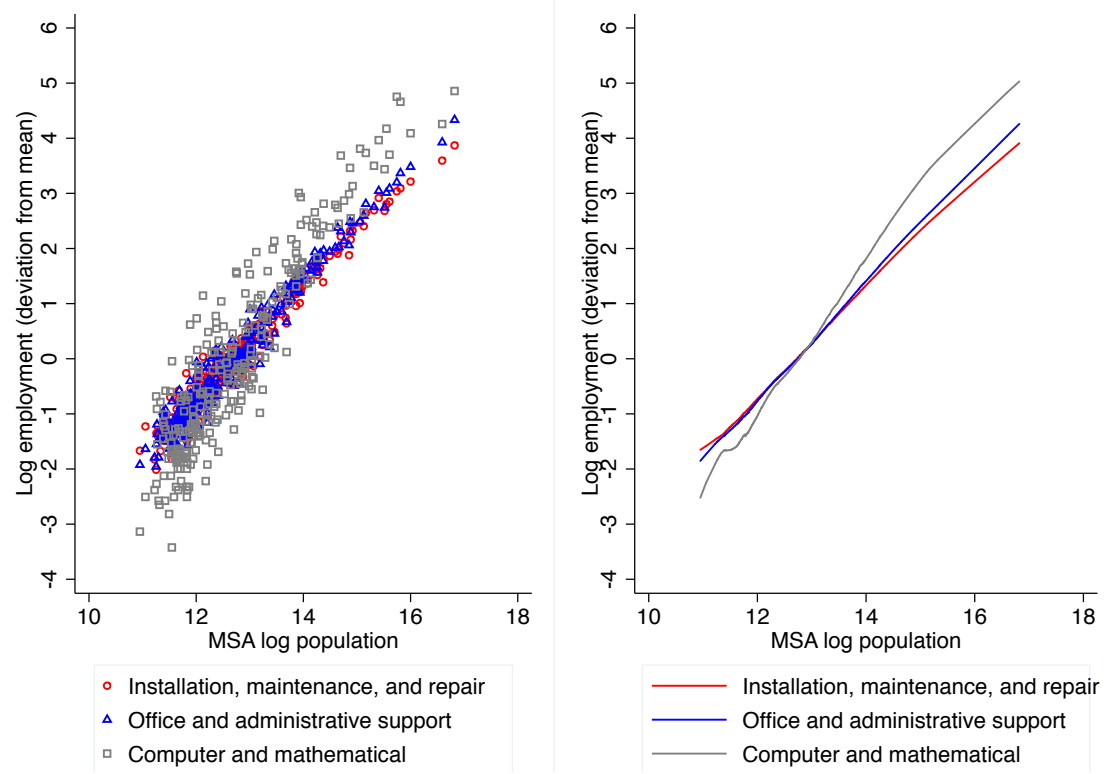

Data source: Occupational Employment Statistics 2000

- Figure 3 plots employment in three manufacturing industries.$^{3}$ Employment in computer and electronic products rises with city size faster than machinery, which in turn rises faster than wood products. On average, computer and electronic employees have about two more years of education than wood products employees.

Figure 3: Employment in three manufacturing industries across US metropolitan areas
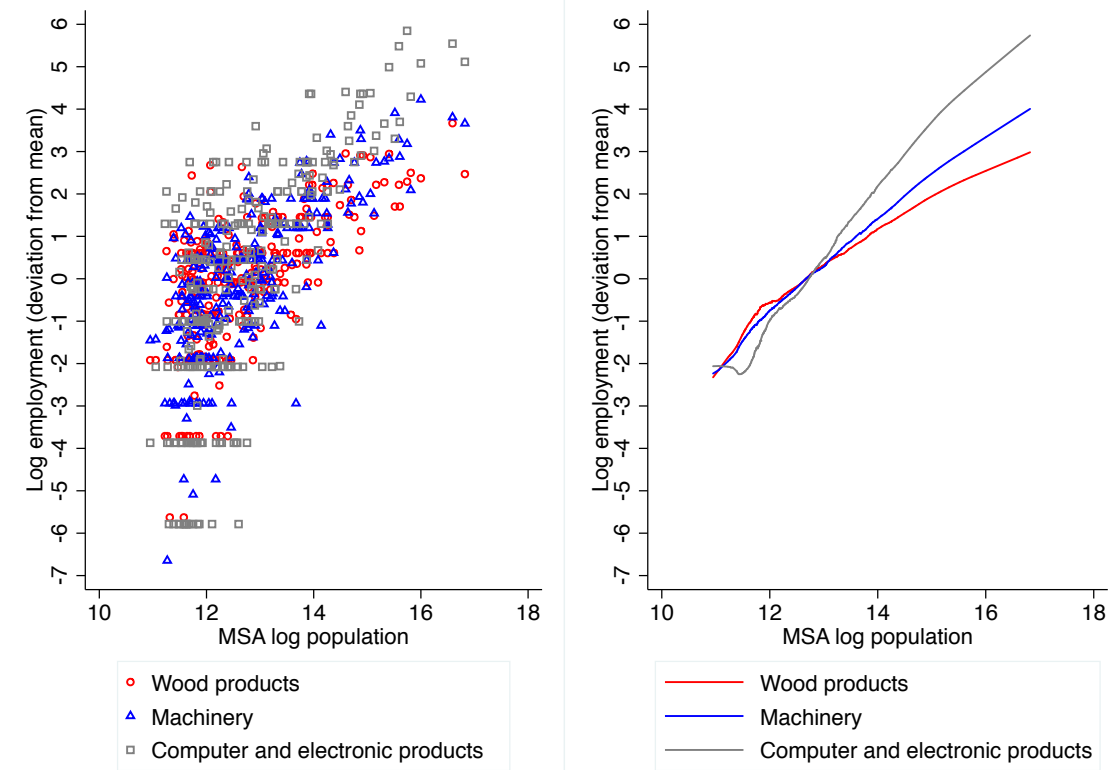

Data source: County Business Patterns 2000

\footnotetext{
${ }^{3}$ The industries are NAICS 321, 333, and 334 in the 2000 County Business Patterns data. Employment levels cluster at particular values due to censored observations. See appendix C describing the data.
} 
Together, these three figures suggest that larger cities are skill abundant and specialize in skill-intensive activities. Explaining these patterns involves fundamental questions about the spatial organization of economic activity. What determines the distribution of skills across cities? What determines the distribution of occupations and industries across cities? How are these two phenomena interrelated? In this paper, we develop a theory describing the comparative advantage of cities that predicts such a pattern of skills and sectors in a manner amenable to empirical investigation.

As we describe in section 2, prior theories describing cities' sectoral composition have overwhelmingly focused on the polar cases in which cities are either completely specialized "industry towns" or perfectly diversified hosts of all economic activities (Helsley and Strange, 2012). Yet Figures 2 and 3 make clear both that reality falls between these poles and that sectoral employment shares are systematically related to cities' sizes. In this paper, we integrate modern trade theory with urban economics by introducing a spatial-equilibrium model in which the comparative advantage of cities is jointly governed by the comparative advantage of individuals and their locational choices. Our theory both describes the intermediate case in which cities are incompletely specialized and relates the pattern of specialization to cities' observable characteristics. It makes strong, testable predictions about the distributions of skills and sectors across cities that we take to the data.

Section 3 introduces our model of a system of cities with heterogeneous internal geographies. Cities are ex ante homogeneous, so cross-city heterogeneity is an emergent outcome of the choices made by freely mobile individuals. Agglomeration economies make cities with larger, more skilled populations exhibit higher total factor productivity (TFP). Locations within cities are heterogeneous and more desirable locations are relatively scarce, as is customary in land-use models (Fujita and Thisse, 2002, Ch 3). These cities are populated by heterogeneous individuals with a continuum of skill types, and these individuals may be employed in a continuum of sectors. Comparative advantage causes more skilled individuals to work in more skill-intensive sectors, as in Sattinger (1975), Costinot (2009), and Costinot and Vogel (2010). There is a complementarity between individual income and locational attractiveness, so more skilled individuals are more willing to pay for more attractive locations and occupy these locations in equilibrium, as in the differential rents model of Sattinger (1979).

In equilibrium, agglomeration, individuals' comparative advantage, and heterogeneity across internal locations within cities combine to deliver a rich set of novel predictions. Agglomeration causes larger cities to have higher TFP, which makes a location within a larger city more attractive than a location of the same innate desirability within a smaller city. For example, the best location within a larger city is more attractive than the best location within a smaller city due to the difference in TFP. Since more skilled individuals occupy more attractive locations, larger cities are skill abundant. The most skilled individuals in the population live only in the largest city and more skilled individuals are more prevalent than less skilled individuals in larger cities, consistent with the pattern shown in Figure11. By individuals' comparative advantage, the most skill-intensive sectors are located exclusively in the largest cities and larger cities specialize in the production of skill-intensive output. More skill-intensive sectors exhibit higher population elasticities of sectoral employment, as suggested in Figures 2 and 3 . Our model therefore predicts an urban hierarchy of skills and sectors. 
We examine the model's predictions about the spatial distribution of skills and sectors across US cities using data from the 2000 Census of Population, County Business Patterns, and Occupational Employment Statistics described in section 4 . We use two empirical approaches. The first involves regression estimates of the population elasticities of educational, occupational, and industrial populations akin to those shown in Figures 1 through 3 . The second involves pairwise comparisons governed by the monotone likelihood ratio property, as per Costinot (2009). ${ }^{4}$

Section 5 reports the results, which provide support for our model's predictions about the spatial pattern of skills and sectors. Characterizing skills in terms of three or nine educational groups, we find that larger cities are skill abundant. Among US-born individuals, cities' skill distributions typically exhibit the monotone likelihood ratio property 5 Characterizing sectors in terms of 21 manufacturing industries or 22 occupational categories, we find that larger cities specialize in skill-intensive sectors. While sectors do not exhibit the monotone likelihood ratio property as reliably as skills, there is systematic variation in cities' sectoral distributions that is consistent with the novel predictions of our theory.

In short, when mobile individuals optimally choose locations and sectors, larger cities will have more skilled populations and thereby comparative advantage in skilled activities. These features are consistent with US data.

\section{Related literature}

Our contributions are related to a diverse body of prior work. Our focus on high-dimensional labor heterogeneity is related to recent developments in labor and urban economics. Our theoretical approach integrates elements from the systems-of-cities literature, land-use theory, and international trade. Our model yields estimating equations and pairwise inequalities describing the comparative advantage of cities that are related to prior reduced-form empirical work in urban economics, despite a contrast in theoretical underpinnings.

Our theory describes a continuum of heterogeneous individuals. A large share of systemsof-cities theories describe a homogeneous population (Abdel-Rahman and Anas, 2004). Most previous examinations of heterogeneous labor have only described two skill levels, typically labeled skilled and unskilled ${ }^{6}$ To describe greater heterogeneity, we assume a continuum of skills, like Behrens, Duranton, and Robert-Nicoud (2010) and Davis and Dingel (2012).7 Understanding the distribution of skills across cities with more than two types is valuable for at least three reasons. First, a large literature in labor economics has described impor-

\footnotetext{
${ }^{4}$ The distributions $f_{c}(\sigma)$ and $f_{c^{\prime}}(\sigma)$ exhibit the monotone likelihood ratio property if, for any $\sigma>\sigma^{\prime}$, $\frac{f_{c}(\sigma)}{f_{c^{\prime}}(\sigma)} \geq \frac{f_{c}\left(\sigma^{\prime}\right)}{f_{c^{\prime}}\left(\sigma^{\prime}\right)}$.

${ }^{5}$ Relative to our theory, foreign-born individuals with less than a high-school education tend to disproportionately locate in large US cities. Data from 1980, when foreign-born individuals were a substantially smaller share of the US population, suggest this reflects particular advantages that large cities offer foreignborn individuals rather than a general tendency for the unskilled to locate in large cities. See section 5.1.2.

${ }^{6} \mathrm{We}$ focus on theories in which labor is heterogeneous in some asymmetric sense (e.g. more skilled individuals have absolute advantage in tasks or more skilled individuals generate greater human-capital spillovers). There are also models describing matching problems, such as Helsley and Strange (1990) and Duranton and Puga (2001), in which labor is heterogeneous in a horizontal characteristic.

Eeckhout, Pinheiro, and Schmidheiny (2011) describe a model with three skill types.
} 
tant empirical developments such as wage polarization, job polarization, and simultaneous changes in between- and within-group inequality that cannot be explained by a model with two homogeneous skill groups (Acemoglu and Autor, 2011). Second, these developments have counterparts in cross-city variation in inequality and skill premia (Baum-Snow and Pavan, 2011; Davis and Dingel, 2012). Third, we document systematic patterns in the crosscity distribution of skills at high levels of disaggregation, which suggests that individuals within broad skill categories are imperfect substitutes. ${ }^{8}$

Our model is a novel integration of systems-of-cities theory with land-use theory. The Alonso-Muth-Mills model of a single city describes a homogeneous population of residents commuting to a central business district (Brueckner, 1987). In that model, higher rents for locations with shorter commutes equalize utility across locations in equilibrium. When individuals are heterogeneous and value the rent-distance tradeoff differently, the single city's equilibrium rent schedule is the upper envelope of individuals' bid-rent functions (von Thünen, 1826; LeRoy and Sonstelie, 1983; Fujita and Thisse, 2002, Ch 3). Models of a system of cities have incorporated the Alonso-Muth-Mills urban structure in which all individuals are indifferent across all locations within a city as a city-level congestion mechanism (Abdel-Rahman and Anas, 2004; Behrens, Duranton, and Robert-Nicoud, 2010). Our novel contribution is to describe multiple cities with internal geographies when individuals are not spatially indifferent across all locations 99 The essential idea is that individuals choosing between living in Chicago or Des Moines simultaneously consider in what parts of Chicago and what parts of Des Moines they might locate. Though these tradeoffs appear obvious, we are not aware of a prior formal analysis. Considering both dimensions simultaneously is more realistic in both the description of the economic problem and the resulting predicted cross-city skill distributions. Since we have a continuum of heterogeneous individuals, we obtain equilibrium rent schedules that are integrals rather than upper envelopes of a discrete number of bid-rent functions 10

Our model belongs to a long theoretical tradition describing factor-supply-driven comparative advantage, dating from the Heckscher-Ohlin theory formalized by Samuelson (1948). In international contexts, theorists have typically taken locations' factor supplies as exogenously endowed. Since individuals are mobile across cities, our theory endogenizes cities' factor supplies while describing how the composition of output is governed by comparative advantage. Our approach to comparative advantage with a continuum of factors and a continuum of sectors follows a large assignment literature and is most closely related to the recent work of Costinot (2009) and Costinot and Vogel (2010).11 While these recent papers assume that countries' factor endowments exhibit the monotone likelihood ratio property, we obtain the result that cities' skill distributions exhibit this property as an equilibrium outcome. Thus, from a theoretical perspective, cities within a country constitute a natural setting to examine these theories of comparative advantage. Moreover, the assumption of a common production

\footnotetext{
${ }^{8} \mathrm{~A}$ long line of empirical work describes cross-city variation in skill distributions in terms of the share of residents who have a college degree (Glaeser, 2008). Most closely related to our work is Hendricks (2011), who finds a weak relationship between cities' industries and college shares.

${ }^{9}$ In order to tractably characterize multiple cities with internal geographies and heterogeneous agents, we neglect the business-vs-residential land-use problem studied by Lucas and Rossi-Hansberg (2002)

${ }^{10}$ Our continuum-by-continuum approach to a differential rents model is in the spirit of Sattinger (1979).

11 Sattinger (1993) surveys the assignment literature.
} 
technology is likely more appropriate within than between economies, and data from a single economy are likely more consistent and comparable than data combined across countries.

The Heckscher-Ohlin model has been the subject of extensive empirical investigation in international economics. A pair of papers describe regional outputs using this framework. Davis and Weinstein (1999) run regressions of regional outputs on regional endowments, employing the framework of Leamer (1984), but they abstract from the issue of labor mobility across regions. Bernstein and Weinstein (2002) consider the two-way links between endowments and outputs, concluding that if we know regions' outputs, we know with considerable precision the inputs used, but not vice versa. For these reasons, traditional Heckscher-Ohlin models did not appear a promising way to explain regional differences in sectoral composition.

Our theory predicts systematic variation in sectoral composition in the form of an urban hierarchy of sectors. Prior systems-of-cities theories have overwhelmingly described polarized sectoral composition: specialized cities that have only one tradable sector and perfectly diversified cities that have all the tradable sectors (Abdel-Rahman and Anas, 2004; Helsley and Strange, 2012). A recent exception is Helsley and Strange (2012), who examine whether the equilibrium level of coagglomeration is efficient. While Helsley and Strange (2012) make minimal assumptions in order to demonstrate that Nash equilibria are generically inefficient when there are interindustry spillovers, we make strong assumptions that yield testable implications about the distribution of sectoral activity across cities.

Our model's equilibrium exhibits a hierarchy of cities and sectors, as larger cities produce a superset of the goods produced in smaller cities. Models in central place theory, dating from Christaller (1933) through Hsu, Holmes, and Morgan (2013), have attributed this hierarchy property to the interaction of industry-specific scale economies and geographic market access based on the distance between firms located in distinct city centers. It is interesting that our model yields the hierarchy property in the absence of both. Our theory links the hierarchy of sectors to a hierarchy of skills shaped by the internal geography of cities, neither of which have been considered in central place theory.

A recent empirical literature has demonstrated significant agglomeration and coagglomeration of industries relative to the null hypothesis of locations being (uniformly) randomly assigned in proportion to local population (Ellison and Glaeser, 1997, Duranton and Overman, 2005; Ellison, Glaeser, and Kerr, 2010). Our model's predictions are consistent with these findings. Since our theory says that sectors are ranked in terms of their relative employment levels, at most one sector could exhibit employment proportionate to total population. All other sectors will exhibit geographic concentration. Similarly, since sectors more similar in skill intensity will exhibit more similar relative employment levels, the cross-city distribution of sectoral employment will be consistent with skill-related coagglomeration. We obtain these results in the absence of industry-specific scale economies and industry-pair-specific interactions or spillovers.

Our empirical work follows directly from our model's predictions about the cross-city distribution of sectoral activity relating cities' and sectors' characteristics. There is a small empirical literature describing variation in cities' sectoral composition, but this work has not been tightly tied to theory. This is likely because theories describing specialized or perfectly diversified cities provide limited guidance to empirical investigations of data that fall between the extremes. Holmes and Stevens (2004) survey the spatial distribution of economic 
activities in North America. In examining the empirical pattern of specialization, they show that agriculture, mining, and manufacturing are disproportionately in smaller cities, while finance, insurance, real estate, professional, and management activities are disproportionately in larger cities. However, they do not reference a model or theoretical mechanism that predicts this pattern to be the equilibrium outcome. Seminal work by Vernon Henderson explores theoretically and empirically the relationship between city size and industrial composition (Henderson, 1991). Henderson (1974) theoretically describes the polar cases of specialized and perfectly diversified cities (Helsley and Strange, 2012), while our model predicts incomplete industrial specialization. Henderson has argued that localization economies link cities' and industries' sizes, while our theory relies on urbanization economies and individuals' comparative advantage.12 Despite these contrasts, our theory yields estimating equations for the population elasticities of sectoral employment that are closely related to the reduced-form regressions of employment shares on population that Henderson (1983) estimated for a few select industries. Our theory provides an explicit microfoundation for these regressions for an arbitrary number of sectors. Moreover, it predicts that we can order these elasticities by skill intensity. It also describes how to compare the sectoral composition of groups of cities ordered by size, nesting the comparison of large and medium-size cities made by Henderson (1997). While our urbanization-based theory abstracts from the localization economies emphasized by Henderson, we believe future work should seek to integrate these distinct approaches.

\section{Model}

We develop a general-equilibrium model in which $L$ heterogeneous individuals choose a city, a location within that city, and a sector in which to produce. There are $C$ discrete cities $(c \in \mathbb{C}=\{1, \ldots, C\})$, a continuum of skills, and a continuum of sectors. We study the consequences for city total factor productivity and the cross-city distributions of skills and sectors.

\subsection{Preferences, production, and places}

Individuals consume a freely traded final good. This final good is the numeraire and produced by combining a continuum of freely traded, labor-produced intermediate goods indexed by $\sigma \in \Sigma$. These have prices $p(\sigma)$ that are independent of location because trade costs are zero. Locations are characterized by their city $c$ and their (inverse) desirability $\delta \in \Delta$, so they have rental prices $r(c, \delta)$.

Final-goods producers have a CES production function

$$
Q=\left\{\int_{\sigma \in \Sigma} B(\sigma)[Q(\sigma)]^{\frac{\epsilon-1}{\epsilon}} d \sigma\right\}^{\frac{\epsilon}{\epsilon-1}},
$$

\footnotetext{
${ }^{12}$ The literature traditionally distinguishes two types of external economies of scale (Henderson, 1987. p.929). Localization economies are within-industry, reflecting the scale of activity in that industry in that location. Urbanization economies are general, reflecting the scale of all economic activity in a location. Beyond scale, Lucas (1988) has stressed the composition of a location's human capital. The agglomeration process generating city-level productivities in our theory incorporates both scale and composition effects.
} 
where the quantity of intermediate good $\sigma$ is $Q(\sigma), \epsilon>0$ is the elasticity of substitution between intermediates, and $B(\sigma)$ is an exogenous technological parameter. The profits of final-goods producers are given by

$$
\Pi=Q-\int_{\sigma \in \Sigma} p(\sigma) Q(\sigma) d \sigma .
$$

Heterogeneous individuals use their labor to produce intermediate goods. There is a mass of $L$ heterogeneous individuals with skills $\omega$ that have the cumulative distribution function $F(\omega)$ and density $f(\omega)$ on support $\Omega \equiv[\underline{\omega}, \bar{\omega}]$. The productivity of an individual of skill $\omega$ in sector $\sigma$ at location $\delta$ in city $c$ is

$$
q(c, \delta, \sigma ; \omega)=A(c) D(\delta) H(\omega, \sigma) .
$$

$A(c)$ denotes city-level total factor productivity, which results from agglomeration and is taken as given by individuals. $D(\delta)$ reflects the productivity effects of location within the city, which in a canonical case is the cost of commuting to the central business district.13 We assume that $D(\delta)$ is continuously differentiable and $D^{\prime}(\delta)<0$, which is just a normalization that higher- $\delta$ locations are less desirable. We assume that $H(\omega, \sigma)$ is strictly log-supermodular in $\omega$ and $\sigma$ and strictly increasing in $\omega \sqrt{14}$ The former governs comparative advantage, so that higher- $\omega$ individuals are relatively more productive in higher- $\sigma$ sectors.$^{15}$ The latter says that absolute advantage is indexed by $\omega$, so that higher- $\omega$ individuals are more productive than lower- $\omega$ individuals in all sectors. Each individual inelastically supplies one unit of labor, so her income is her productivity times the price of the output produced, $q(c, \delta, \sigma ; \omega) p(\sigma)$.

Locations within each city are heterogeneous, with the desirability of a location indexed by $\delta \geq 0$. The most desirable location is denoted $\delta=0$, so higher values of $\delta$ denote greater distance from the ideal location. The supply of locations with desirability greater than $\delta$ is $S(\delta){ }^{16}$ This is a strictly increasing function, since the supply of available locations increases as one lowers one's minimum standard of desirability. $S(0)=0$, since there are no locations better than the ideal. We assume $S(\delta)$ is twice continuously differentiable. Locations are owned by absentee landlords who spend their rental income on the final good. The city has sufficient land capacity that everyone can reside in the city and the least desirable locations are unoccupied. We normalize the reservation value of unoccupied locations to zero, so $r(c, \delta) \geq 0$.

Individuals choose their city $c$, location $\delta$, and sector $\sigma$ to maximize utility. An individual's utility depends on their consumption of the numeraire final good, which is their income

\footnotetext{
${ }^{13}$ As written, $D(\delta)$ indexes the desirability of the location for its productive advantages, but a closely related specification makes $D(\delta)$ describe a location's desirability for its consumption value. The production and consumption interpretations yield very similar results but differ slightly in functional form. For expositional clarity, we use the production interpretation given by equations $(3)$ and $(4)$ in describing the model in the main text and present the consumption interpretation in appendix $\mathrm{A}$.

${ }^{14}$ In $\mathbb{R}^{2}$, a function $H(\omega, \sigma)$ is strictly log-supermodular if $\omega>\omega^{\prime}, \sigma>\sigma^{\prime} \Rightarrow H(\omega, \sigma) H\left(\omega^{\prime}, \sigma^{\prime}\right)>$ $H\left(\omega, \sigma^{\prime}\right) H\left(\omega^{\prime}, \sigma\right)$.

${ }^{15}$ We refer to higher- $\omega$ individuals as more skilled and higher- $\sigma$ sectors as more skill-intensive.

${ }^{16}$ In the special case of the classical von Thünen model, $\delta$ describes physical distance from the central business district and the supply is $S(\delta)=\pi \delta^{2}$.
} 
after paying their locational cost:

$$
U(\omega, c, \delta, \sigma)=A(c) D(\delta) H(\omega, \sigma) p(\sigma)-r(c, \delta)
$$

Denote the endogenous quantity of individuals of skill $\omega$ residing in city $c$ at location $\delta$ and working in sector $\sigma$ by $L \times f(\omega, c, \delta, \sigma)$.

City-level TFP, $A(c)$, reflects agglomeration gains derived from both population size and composition. $A(c)$ is higher when a city contains a larger and more skilled population. Denote the endogenous quantity of individuals of skill $\omega$ residing in city $c$ by $L \times f(\omega, c)=$ $\int_{\sigma \in \Sigma} \int_{\delta \in \Delta} f(\omega, c, \delta, \sigma) d \delta d \sigma$. Total factor productivity is

$$
A(c)=J\left(L \int_{\omega \in \Omega} j(\omega) f(\omega, c) d \omega\right),
$$

where $J(\cdot)$ is a positive, strictly increasing function and $j(\omega)$ is a positive, non-decreasing function.

\subsection{Equilibrium}

In a competitive equilibrium, individuals maximize utility, final-good producers and landowners maximize profits, and markets clear. Individual maximize their utility by their choices of city, location, and sector such that

$$
f(\omega, c, \delta, \sigma)>0 \Longleftrightarrow\{c, \delta, \sigma\} \in \arg \max U(\omega, c, \delta, \sigma) .
$$

Profit maximization by final-good producers yields demands for intermediates

$$
Q(\sigma)=I\left(\frac{p(\sigma)}{B(\sigma)}\right)^{-\epsilon}
$$

where $I \equiv L \sum_{c} \int_{\sigma} \int_{\omega} \int_{\delta} q(\omega, c, \delta, \sigma) p(\sigma) f(\omega, c, \delta, \sigma) d \delta d \omega d \sigma$ denotes total income and these producers' profits are zero. Profit maximization by absentee landlords engaged in Bertrand competition causes unoccupied locations to have rental prices of zero,

$$
r(c, \delta) \times\left(S^{\prime}(\delta)-L \int_{\sigma \in \Sigma} \int_{\omega \in \Omega} f(\omega, c, \delta, \sigma) d \omega d \sigma\right)=0 \forall c \forall \delta
$$

Market clearing requires the endogenous quantity of individuals of skill $\omega$ residing in city $c$ at location $\delta$ and working in sector $\sigma, L \times f(\omega, c, \delta, \sigma)$, to be such that the supply of a location type is greater than or equal to its demand, the demand and supply of intermediate goods are equal, and every individual lives somewhere.

$$
\begin{gathered}
S^{\prime}(\delta) \geq L \int_{\omega \in \Omega} \int_{\sigma \in \Sigma} f(\omega, c, \delta, \sigma) d \sigma d \omega \quad \forall c \forall \delta \\
Q(\sigma)=\sum_{c \in \mathbb{C}} Q(\sigma, c)=L \sum_{c \in \mathbb{C}} \int_{\omega \in \Omega} \int_{\delta \in \Delta} q(c, \delta, \sigma ; \omega) f(\omega, c, \delta, \sigma) d \omega d \delta \quad \forall \sigma
\end{gathered}
$$




$$
f(\omega)=\sum_{c \in \mathbb{C}} f(\omega, c)=\sum_{c \in \mathbb{C}} \int_{\sigma \in \Sigma} \int_{\delta \in \Delta} f(\omega, c, \delta, \sigma) d \delta d \sigma \quad \forall \omega
$$

A competitive equilibrium is a set of functions $Q: \Sigma \rightarrow \mathbb{R}^{+}, f: \Sigma \times \mathbb{C} \times \Delta \times \Omega \rightarrow \mathbb{R}^{+}$, $A: \mathbb{C} \rightarrow \mathbb{R}^{+}, r: \mathbb{C} \times \Delta \rightarrow \mathbb{R}^{+}$, and $p: \Sigma \rightarrow \mathbb{R}^{+}$such that conditions (6) through (11) hold.

\subsection{An autarkic city}

We begin by considering a single city, denoted $c$, with exogenous population $L(c)$ and skill distribution $F(\omega)$. With fixed population, autarky TFP is fixed by equation (5). We describe individuals' choices of sectors and locations to solve for the autarkic equilibrium.

To solve, we exploit the fact that locational and sectoral argument enters individuals' utility functions separably. Individuals' choices of their sectors are independent of their locational decisions:

$$
\arg \max _{\sigma} A(c) D(\delta) H(\omega, \sigma) p(\sigma)-r(c, \delta)=\arg \max _{\sigma} H(\omega, \sigma) p(\sigma)
$$

Taking prices $p(\sigma)$ as given, define the assignment function $M(\omega)=\arg \max _{\sigma} H(\omega, \sigma) p(\sigma)$ so that we can write $G(\omega) \equiv H(\omega, M(\omega)) p(M(\omega)) \cdot{ }^{17}$ By absolute advantage, more skilled individuals earn higher nominal incomes and $G(\omega)$ is a strictly increasing function ${ }^{18}$

Individuals' choices of their locations are related to their sectoral decisions in the sense that willingness to pay for more desirable locations depends on the skill component of income $G(\omega)$. Within the city, individual choose their optimal location:

$$
\max _{\delta} A(c) D(\delta) G(\omega)-r(c, \delta)
$$

Competition among landlords ensures that the most desirable locations are those occupied, so the least desirable occupied site $\bar{\delta}(c) \equiv \max _{\delta}\{\delta: f(\omega, c, \delta, \sigma)>0\}$ in a city of population $L(c)$ is defined by $L(c)=S(\bar{\delta}(c))$. More desirable locations have higher rental prices.

Lemma 1 (Populated locations). In equilibrium, $S(\delta)=L \int_{0}^{\delta} \int_{\sigma \in \Sigma} \int_{\omega \in \Omega} f(\omega, c, x, \sigma) d \omega d \sigma d x \forall \delta \leq$ $\bar{\delta}(c), r(c, \delta)$ is strictly decreasing in $\delta \forall \delta<\bar{\delta}(c)$, and $r(c, \bar{\delta}(c))=0$.

Individuals of higher skill have greater willingness to pay for more desirable locations. That is, $\frac{\partial^{2}}{\partial \delta \partial \omega} A(c) D(\delta) G(\omega)<0$ because locational advantages complement individual productivity. As a result, in equilibrium higher- $\omega$ individuals occupy lower- $\delta$ locations.

Lemma 2 (Autarky locational assignments). In autarkic equilibrium, there exists a continuous and strictly decreasing locational assignment function $N: \Delta \rightarrow \Omega$ such that $f(\omega, c, \delta, \sigma)>$ $0 \Longleftrightarrow N(\delta)=\omega, N(0)=\bar{\omega}$ and $N(\bar{\delta}(c))=\underline{\omega}$.

\footnotetext{
${ }^{17}$ Lemma 1 of Costinot and Vogel (2010) shows that strict log-supermodularity of $H(\omega, \sigma)$ is sufficient for $M(\omega)$ to be continuous and strictly increasing for any price schedule $p(\sigma)$.

${ }^{18}$ Absolute advantage across all sectors is far from necessary. The weaker condition that productivity is increasing in skill at the equilibrium assignments, $\frac{\partial}{\partial \omega} H(\omega, M(\omega))>0$, is sufficient.
} 
This assignment function is obtained by equating supply and demand of locations:

$$
\begin{aligned}
S(\delta) & =L \int_{0}^{\delta} \int_{\sigma \in \Sigma} \int_{\omega \in \Omega} f(\omega, c, x, \sigma) d \omega d \sigma d x \\
\Rightarrow N(\delta) & =F^{-1}\left(\frac{L(c)-S(\delta)}{L(c)}\right)
\end{aligned}
$$

Given individuals' equilibrium locations within the city, the schedule of locational rental prices supporting these assignments comes from combining individuals' utility-maximizing decisions and the boundary condition $r(c, \bar{\delta}(c))=0$.

Lemma 3 (Autarky locational prices). In autarkic equilibrium, $r(c, \delta)$ is continuously differentiable on $\delta \geq 0$ and given by $r(c, \delta)=-A(c) \int_{\delta}^{\bar{\delta}(c)} D^{\prime}(t) G(N(t)) d t$ for $\delta \leq \bar{\delta}(c)$.

The properties of interest in a competitive equilibrium are characterized by the assignment functions $M$ and $N$. In the autarkic equilibrium, more skilled individuals work in more skill-intensive sectors and live in more desirable locations.

Figure 4 illustrates the familiar von Thünen disc example, which captures many of the important properties of the model. The center of the disc is the $\delta=0$ location and the supply of locations at least as good as $\delta$ is $S(\delta)=\pi \delta^{2}$. The radius of the disc, $\bar{\delta}(c)$ or the "city limit", is determined by the total population size such that $L(c)=\pi \bar{\delta}(c)^{2}$. The best available location, $\delta=0$, is occupied by the most skilled individual, $\bar{\omega}$. The least desirable occupied location, the edge of the disc, is occupied by the least skilled individual, $\underline{\omega}$. Rental prices at the city limit are zero, and rental prices of locations closer to the center of the disc are given by integrating the marginal benefit of moving closer to the center as valued by the individual occupying each location.

Figure 4: Autarky equilibrium for the von Thünen disc

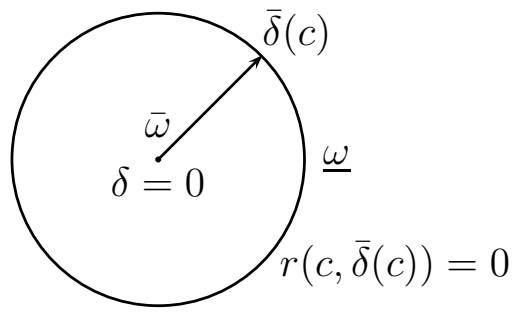

$$
\begin{aligned}
& L(c)=\pi \bar{\delta}(c)^{2} \\
& r(c, \delta)=-A(c) \int_{\delta}^{\bar{\delta}(c)} D^{\prime}(t) G(N(t)) d t
\end{aligned}
$$

\subsection{A system of cities}

The previous section described a single city with an exogenous population. We now describe a system of cities in which these populations are endogenously determined in spatial equilibrium. Take cities' TFPs, which will be endogenously determined in equilibrium, as given 
for now and order the cities so that $A(C) \geq A(C-1) \geq \cdots \geq A(2) \geq A(1)$ In autarky, $\delta$ was a sufficient statistic for the attractiveness of a location. Now a location's attractiveness, which we denote by $\gamma$, depends both on city-level TFP and its innate desirability within the city.

Definition 1. The attractiveness of a location in city $c$ of desirability $\delta$ is $\gamma=A(c) D(\delta)$.

Cities with higher TFP have larger populations. Consider two cities, $c$ and $c^{\prime}$, that differ in productivity, with $A(c)>A\left(c^{\prime}\right)$. The city with greater TFP will have greater population, $L(c)>L\left(c^{\prime}\right)$. If it did not, the least desirable occupied location in city $c$ would be more desirable than the least desirable occupied location in city $c^{\prime}, \bar{\delta}(c) \leq \bar{\delta}\left(c^{\prime}\right)$, since the supply of locations, $S(\delta)$, is common across cities. Since TFP is also higher in $c$, this would make the least attractive occupied location in city $c$ more attractive than the least attractive occupied location in city $c^{\prime}, A(c) D(\bar{\delta}(c))>A\left(c^{\prime}\right) D\left(\bar{\delta}\left(c^{\prime}\right)\right)$. In equilibrium, the least desirable occupied location in each city has a price of zero, $r(c, \bar{\delta}(c))=r\left(c^{\prime}, \bar{\delta}\left(c^{\prime}\right)\right)=0$, by lemma 1. In that case, every individual would agree that living in $c$ at $\bar{\delta}(c)$ is strictly better than living in $c^{\prime}$ at $\bar{\delta}\left(c^{\prime}\right)$ (because $A(c) D(\bar{\delta}(c)) G(\omega)>A\left(c^{\prime}\right) D\left(\bar{\delta}\left(c^{\prime}\right)\right) G(\omega)$ ), which contradicts the definition of $\bar{\delta}\left(c^{\prime}\right)$ as an occupied location. So the city with higher TFP must have a larger population.

A smaller city's locations are a subset of those in a larger city in terms of attractiveness. For every location in the less populous city, there is a location in the more populous city that is equally attractive. The location in city $c^{\prime}$ of desirability $\delta^{\prime}$ is equivalent to a location $\delta$ in city $c$, given by $A(c) D(\delta)=A\left(c^{\prime}\right) D\left(\delta^{\prime}\right)$. The equally attractive location in the larger city has higher TFP but lower innate desirability. That is, an individual who is indifferent between Chicago and Des Moines lives closer to the most desirable location in Des Moines than the most desirable location in Chicago, $\delta^{\prime}=D^{-1}\left(\frac{A(c)}{A\left(c^{\prime}\right)} D(\delta)\right)<\delta$. The more populous city also has locations that are strictly more attractive than the best location in the less populous city; locations of attractiveness $\gamma>A\left(c^{\prime}\right) D(0)$ are found in $c$ and not in $c^{\prime}$. In equilibrium, two locations of equal attractiveness must have the same price, so we can describe the rental price of a location of attractiveness $\gamma$ as $r_{\Gamma}(\gamma)$.

To characterize locational assignments and prices in the system of cities, we first characterize assignments and prices in terms of $\gamma$. The solution is analogous to that derived in the autarkic case. We then translate these assignments and prices into functions of $c$ and $\delta$.

Individuals of higher skill have greater willingness to pay for more attractive locations, so in equilibrium higher- $\omega$ individuals live in higher- $\gamma$ locations.

Lemma 4 (Locational assignments). In equilibrium, there exists a continuous and strictly increasing locational assignment function $K: \Gamma \rightarrow \Omega$ such that $f(\omega, c, \delta, \sigma)>0 \Longleftrightarrow$ $A(c) D(\delta)=\gamma$ and $K(\gamma)=\omega$, where $K(\underline{\gamma})=\underline{\omega}$, and $K(\bar{\gamma})=\bar{\omega}$.

To obtain an explicit expression for $K: \Gamma \rightarrow \Omega$, we can denote the supply of locations offering benefits $\gamma$ or greater as $S_{\Gamma}(\gamma)$. The supply function is

$$
S_{\Gamma}(\gamma)=\sum_{c: A(c) D(0) \geq \gamma} S\left(D^{-1}\left(\frac{\gamma}{A(c)}\right)\right)
$$

\footnotetext{
${ }^{19}$ Individuals take these TFPs as given. For now, we can assume these differences in total factor productivity are exogenously given. We describe their endogenous determination in section 3.6.
} 
By definition $S_{\Gamma}(\bar{\gamma})=0$ and by the fact that the best locations are populated $S_{\Gamma}(\gamma)=$ L. Lemmas 1 and 4 allow us to say that $S_{\Gamma}(\gamma)=L \int_{\gamma}^{\bar{\gamma}} f(K(x)) K^{\prime}(x) d x$, so $K(\bar{\gamma})=$ $F^{-1}\left(\frac{L-S_{\Gamma}(\gamma)}{L}\right)$. These locational assignments yield an expression for equilibrium locational prices.

Lemma 5 (Locational prices). In equilibrium, $r_{\Gamma}(\gamma)$ is continuously differentiable on $[\underline{\gamma}, \bar{\gamma}]$ and given by $r_{\Gamma}(\gamma)=\int_{\underline{\gamma}}^{\gamma} G(K(x)) d x$.

Therefore, the determination of locational assignments and prices within the system of cities is analogous to determining these locational assignments and prices for an autarkic city with a supply of locations that is the sum of locations across the system of cities. The task that remains is to translate these assignments and prices from $\gamma$ back to $c, \delta$.

The city limit $\bar{\delta}(c)=D^{-1}\left(\frac{\gamma}{A(c)}\right)$. Since we are not focused on rental prices, a sufficient characterization is $r(c, \delta)=r_{\Gamma}(A(c) D(\delta))$. For locational assignments, we obtain an explicit expression that characterizes cities' skill distributions in terms of $\omega$ and $c$.

Lemma 6 (A city's skill distribution). The population of individuals of skill $\omega$ in city $c$ is

$$
f(\omega, c)= \begin{cases}\frac{-K^{-1^{\prime}}(\omega)}{A(c) L} D^{-1^{\prime}}\left(\frac{K^{-1}(\omega)}{A(c)}\right) S^{\prime}\left(D^{-1}\left(\frac{K^{-1}(\omega)}{A(c)}\right)\right) & \text { if } A(c) D(0) \geq K^{-1}(\omega) \\ 0 & \text { otherwise }\end{cases}
$$

The relative populations of individuals of skill $\omega$ depends on the relative supply of locations of attractiveness $K^{-1}(\omega)$. Since higher- $\omega$ individuals live in more attractive locations and the most attractive locations are found exclusively in the larger city, there is an interval of high- $\omega$ individuals who reside exclusively in the larger city. Individuals of abilities below this interval are found in both cities, and individuals of equal skill reside in equally attractive locations that have equal rental prices.

Figure 5 illustrates an example in which the system consists of two cities that are von Thünen discs with $A(c)>A\left(c^{\prime}\right)$. The sum of the areas of the two discs equals the total population, and the higher-TFP city has a city limit that is more distant from its center. The most attractive location, $\delta=0$ in city $c$, is occupied by the most skilled individual, $\bar{\omega}$. The least attractive occupied locations, the edges of the two discs, are occupied by the least skilled individuals, $\underline{\omega}$. Denote the individual living at the most attractive location within city $c^{\prime}$ by $\tilde{\omega}$. Individuals of this skill type also live in the higher-TFP city at distance $\tilde{\delta}$. Individuals of skill $\omega>\tilde{\omega}$ live only in city $c$, in locations less than $\tilde{\delta}$ from the center of the disc. Individuals of skill $\omega \leq \tilde{\omega}$ live in both cities. Rental prices of equally attractive location are equal across the two cities. 
Figure 5: Two-city equilibrium with von Thünen discs

Low TFP city
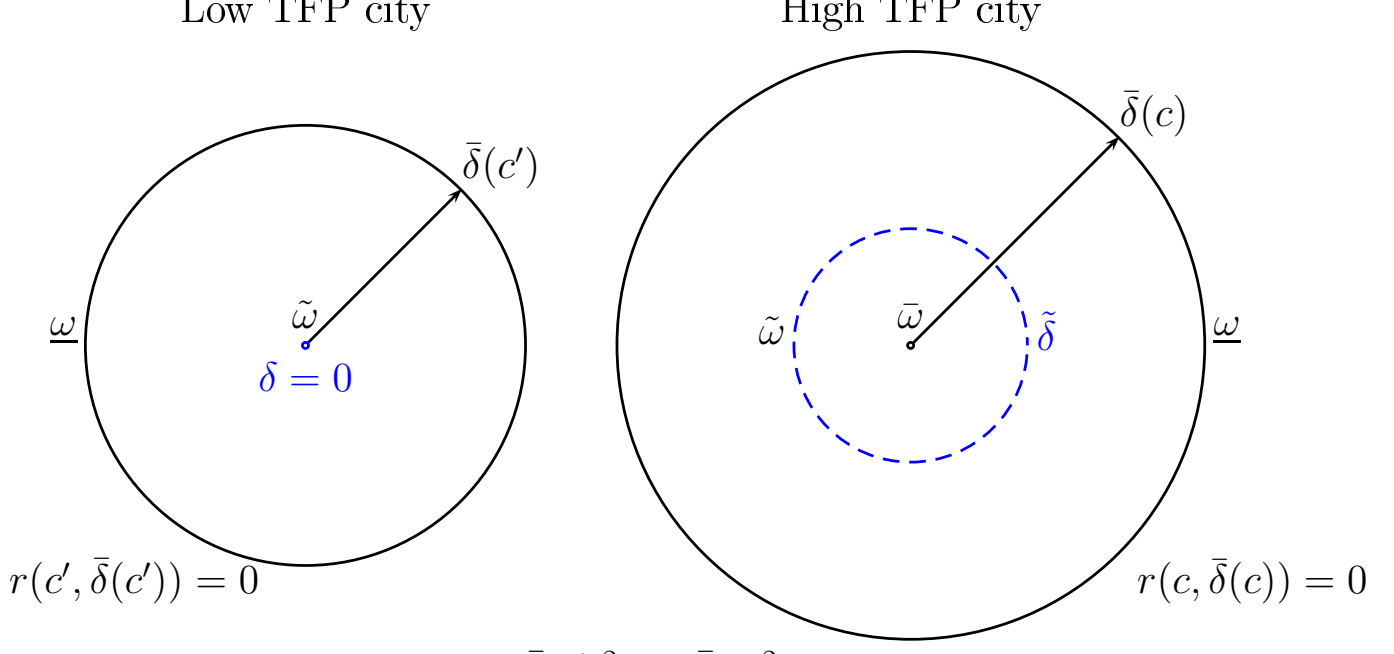

$$
\begin{gathered}
L=\pi \bar{\delta}\left(c^{\prime}\right)^{2}+\pi \bar{\delta}(c)^{2} \\
\tilde{\gamma}=A\left(c^{\prime}\right) D(0)=A(c) D(\tilde{\delta}) \\
r\left(c^{\prime}, 0\right)=r(c, \tilde{\delta})
\end{gathered}
$$

\subsection{Cities' populations and sectors}

When more desirable locations within cities are scarcer, our model implies that larger cities will exhibit relatively more skilled populations and produce relatively more in skill-intensive sectors. The first result comes from large cities offering more attractive locations, which are occupied by higher-income individuals in equilibrium. Higher-income individuals are more skilled due to our assumption of absolute advantage. The second result comes from larger cities' TFP advantages being sector-neutral, so that sectoral composition is governed by skill composition.

Larger cities have relatively more skilled populations. We have already shown that the most skilled individuals live exclusively in the largest city because it offers the most attractive locations. What about individuals of skill levels found in multiple cities? The distribution of skills is governed by the interaction of city TFPs, $A(c)$, and the supply of locations within cities yielding at least $D(\delta)=z$, which is $S\left(D^{-1}(z)\right.$ ). We say that the latter is well-behaved when more desirable locations are scarcer and their distribution satisfies a common regularity condition 20

Definition 2. The supply of locations within cities is well-behaved if the density $-\frac{\partial}{\partial z} S\left(D^{-1}(z)\right)$ is decreasing and log-concave.

When the supply of locations within cities is well-behaved, more skilled individuals are relatively more prevalent in larger cities throughout the skill distribution. Consider a location in Des Moines, which has attractiveness $\gamma^{\prime}$. Higher-TFP Chicago has more locations of attractiveness $\gamma \geq \gamma^{\prime}$, since $S(\delta)$ is increasing. If $S\left(D^{-1}(z)\right)$ is well-behaved, then Chicago's

\footnotetext{
${ }^{20} \mathrm{Log}$-concavity is most commonly used in economics in the context of probability distributions (Bagnoli and Bergstrom, 2005).
} 
supply of $\gamma^{\prime}$ locations relative to $\gamma^{\prime \prime}$ locations, for any $\gamma^{\prime}>\gamma^{\prime \prime}$, is greater than that of Des Moines. Since higher- $\omega$ individuals live in higher- $\gamma$ locations, this means the population of Chicago is relatively more skilled when comparing any two skill types. Proposition 1 states this result for a system of cities; its proof is in appendix B.

Proposition 1 (Skill abundance). If the supply of locations within cities is well-behaved, then $f(\omega, c)$ is log-supermodular.

Figure 6: Two-city illustration of Proposition 1 result Low TFP city

High TFP city
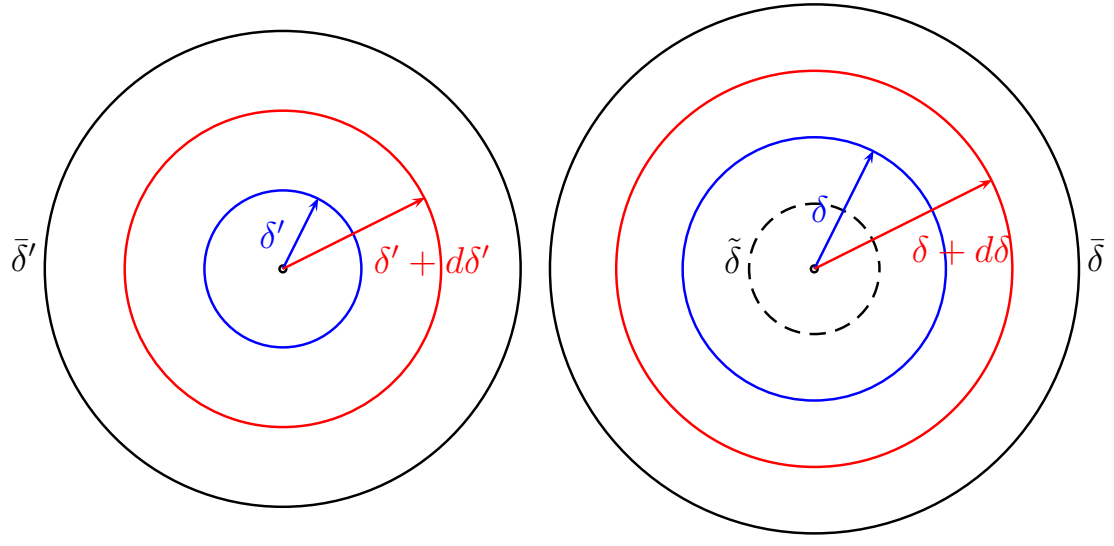

$$
\begin{gathered}
A\left(c^{\prime}\right) D\left(\delta^{\prime}\right)=A(c) D(\delta) \\
A\left(c^{\prime}\right) D\left(\delta^{\prime}+d \delta^{\prime}\right)=A(c) D(\delta+d \delta)
\end{gathered}
$$

To illustrate the logic of Proposition 1, we consider the special case of two circular von Thünen cities and linear commuting costs. ${ }^{21}$ The two cities differ in TFP, with $A(c)>A\left(c^{\prime}\right)$, so the radius of city $c$ is larger than that of city $c^{\prime}, \bar{\delta}(c)>\bar{\delta}\left(c^{\prime}\right)$, as depicted in Figure 6 . Consider two locations $\delta$ and $\delta^{\prime}$ that are equally attractive, such that $A(c) D(\delta)=A\left(c^{\prime}\right) D\left(\delta^{\prime}\right)$. These locations are the blue circles in Figure 6, with $\delta>\delta^{\prime}$. Now consider an arbitrary, less desirable location at distance $\delta+d \delta$. The equivalent location in city $c^{\prime}$, denoted by $\delta^{\prime}+d \delta^{\prime}$, can be identified using $A(c) D(\delta+d \delta)=A\left(c^{\prime}\right) D\left(\delta^{\prime}+d \delta^{\prime}\right)$. These locations are the red circles in Figure 6. Each city's relative supply of red locations to blue locations is the ratio of their circumferences: $\frac{\delta+d \delta}{\delta}$ and $\frac{\delta^{\prime}+d \delta^{\prime}}{\delta^{\prime}}$, respectively. The supply of the worse location is relatively greater in the smaller city. By the linearity of $D(\cdot)$, we know that $\frac{d \delta}{d \delta^{\prime}}=\frac{A\left(c^{\prime}\right)}{A(c)}<1$. Therefore $\frac{\delta^{\prime}+d \delta^{\prime}}{\delta^{\prime}}=1+\frac{d \delta^{\prime}}{\delta^{\prime}}>1+\frac{d \delta}{\delta}=\frac{\delta+d \delta}{\delta}$, since $\delta>\delta^{\prime}$ and $d \delta^{\prime}>d \delta$. More attractive locations are relatively more abundant in the larger city. Since equally attractive locations are occupied by individuals of equal skill, the larger city's population is relatively skilled.

Our next set of results concern the sectoral output of cities. Since individuals' choices of sectors are independent of their cities and locations, the cross-city skill distribution governs the cross-city output distribution. Larger cities are relatively skill abundant and more skilled

\footnotetext{
${ }^{21}$ When $S(\delta)=\pi \delta^{2}$ and $D(\delta)=d_{1}-d_{2} \delta,-\frac{\partial}{\partial z} S\left(D^{-1}(z)\right)=\frac{2 \pi}{d_{2}^{2}}\left(d_{1}-z\right)$ is decreasing and log-concave.
} 
individuals work in more skill-intensive sectors, so larger cities produce relatively more in skill-intensive sectors.

These patterns of specialization and trade are closely related to the high-dimensional model of endowment-driven comparative advantage introduced by Costinot (2009), but in our setting cities' populations are endogenously determined. ${ }^{22}$ Since at equilibrium larger cities' productivity advantages are sector-neutral differences in total factor productivity, $f(\omega, c)$ is log-supermodular, and $H(\omega, \sigma)$ is log-supermodular, our economy's equilibrium satisfies Definition 4, Assumption 2, and Assumption 3 of Costinot (2009) ${ }^{23}$ The result is that $Q(\sigma, c)$ is log-supermodular. As shown by Corollaries 2 and 3 in Costinot (2009), we can therefore rank the relative output $(Q(\sigma, c))$, employment $\left(f(\sigma, c) \equiv \int_{\delta \in \Delta} \int_{\omega \in \Omega} f(\omega, c, \delta, \sigma) d \omega d \delta\right)$, and revenue $(R(\sigma, c) \equiv p(\sigma) Q(\sigma, c))$ of any two sectors in any two cities.

Proposition 2 (Comparative Advantage). If $f(\omega, c)$ is log-supermodular, then $Q(\sigma, c)$, $f(\sigma, c)$, and $R(\sigma, c)$ are log-supermodular, so that for $c \geq c^{\prime}$ and $\sigma \geq \sigma^{\prime}$, the following inequalities hold true

$$
\begin{gathered}
Q(\sigma, c) Q\left(\sigma^{\prime}, c^{\prime}\right) \geq Q\left(\sigma, c^{\prime}\right) Q\left(\sigma^{\prime}, c\right) \\
f(\sigma, c) f\left(\sigma^{\prime}, c^{\prime}\right) \geq f\left(\sigma, c^{\prime}\right) f\left(\sigma^{\prime}, c\right) \\
R(\sigma, c) R\left(\sigma^{\prime}, c^{\prime}\right) \geq R\left(\sigma, c^{\prime}\right) R\left(\sigma^{\prime}, c\right)
\end{gathered}
$$

These inequalities characterize the pattern of comparative advantage across cities. 24

\subsection{Endogenizing cities' total factor productivities}

Our exposition of equilibrium in sections 3.4 and 3.5 took cities' total factor productivities as exogenously given. When the conditions of Proposition 1 are satisfied, a city that has higher total factor productivity $A(c)$ is larger and has a skill distribution $f(\omega, c)$ that likelihood ratio dominates those of cities with lower TFPs. Thus, this spatial pattern can be supported by endogenous productivity processes that make the city-level characteristic $A(c)$ higher when the city contains a larger and more skilled population, such as the class of agglomeration functions described by equation (5). Numerous agglomeration processes may generate such productivity benefits, and we do not attempt to distinguish between them here.

\footnotetext{
${ }^{22}$ Assumption 2 in Costinot (2009)'s factor endowment model is that countries' exogenous endowments are such that countries can be ranked according to the monotone likelihood ratio property. Proposition 1 identifies sufficient conditions for cities' equilibrium skill distributions to exhibit this property.

${ }^{23}$ Definition 4 of Costinot (2009) requires that factor productivity vary across countries (cities) in a Hicksneutral fashion. Since productivity $A(c) D(\delta)$ varies both across and within cities, our production function $q(c, \delta, \sigma ; \omega)$ does not satisfy this requirement for arbitrary locational assignments. However, in equilibrium, our economy does exhibit this property. In the production interpretation of $D(\delta)$, equilibrium productivity $q(c, \delta, \sigma ; \omega)=K^{-1}(\omega) H(\omega, \sigma)$ does not vary across $\omega$-occupied locations and is log-supermodular in $\omega$ and $\sigma$. In the notation of equation (6) in Costinot (2009), $a(\gamma)=1$ and $h(\omega, \sigma)=K^{-1}(\omega) H(\omega, \sigma)$, satisfying Definition 4 and Assumption 3.

${ }^{24} \mathrm{~A}$ traditional definition of comparative advantage refers to countries' autarkic prices. In our setting, autarky means prohibiting both trade of intermediate goods and migration between cities. Since individuals are spatially mobile, cities do not have "factor endowments", and we must specify the autarkic skill distributions. If we consider an autarkic equilibrium with the skill distributions from the system-of-cities equilibrium, then larger cities have lower relative autarkic prices for higher- $\sigma$ goods because they are skill abundant in the MLRP sense, as shown by Costinot and Vogel (2010, p. 782).
} 


\section{Empirical approach and data description}

We examine the predictions of Propositions 1 and 2 using two approaches. The first involves regression estimates of the population elasticities of educational, occupational, and industrial populations. The second involves pairwise comparisons governed by the monotone likelihood ratio property.

Empirically testing our model requires data on cities' skill distributions, sectors' skill intensities, and cities' sectoral employment. We use public-use microdata from the US Census of Population to identify the first two. The latter is described by data from County Business Patterns and Occupational Employment Statistics. The Census of Population describes individuals' educational attainments, geographic locations, places of birth, occupations, and industries. County Business Patterns describes cities' industrial employment. Occupational Employment Statistics describes cities' occupational employment. See appendix C for details of the geographies covered by these data sources.

\subsection{Empirical tests}

Propositions 1 and 2 say that the distribution of skills across cities, $f(\omega, c)$, and the distribution of sectoral employment across cities, $f(\sigma, c)$, are log-supermodular functions. Logsupermodularity has many implications; we focus on two that are amenable to empirical testing. If the function $f(\nu, c)$ is log-supermodular, then

- a linear regression $\ln f(\nu, c)=\alpha_{\nu}+\beta_{\nu} \ln L(c)+\epsilon_{\nu, c}$ in which $\alpha_{\nu}$ are fixed effects and $L(c)$ is city population yields $\beta_{\nu} \geq \beta_{\nu^{\prime}} \Longleftrightarrow \nu \geq \nu^{\prime}$;

- if $\mathcal{C}$ and $\mathcal{C}^{\prime}$ are distinct sets and $\mathcal{C}$ is greater than $\mathcal{C}^{\prime}\left(\inf _{c \in \mathcal{C}} L(c)>\sup _{c^{\prime} \in \mathcal{C}^{\prime}} L\left(c^{\prime}\right)\right)$, then $\sum_{c \in \mathcal{C}} f(\nu, c) \sum_{c^{\prime} \in \mathcal{C}^{\prime}} f\left(\nu^{\prime}, c^{\prime}\right) \geq \sum_{c \in \mathcal{C}} f\left(\nu^{\prime}, c\right) \sum_{c^{\prime} \in \mathcal{C}^{\prime}} f\left(\nu, c^{\prime}\right) \forall \nu>\nu^{\prime}$.

The first implication, which we will refer to as the "elasticity test," says that the citypopulation elasticity of the population of a skill type in a city $f(\omega, c)$ is increasing in skill $\omega{ }^{25}$ Similarly, the population elasticity of sectoral employment $f(\sigma, c)$ is increasing in skill intensity $\sigma$. The elasticity test examines the patterns suggested by Figures 1 through 3 . where steeper slopes correspond to higher elasticities. Our theory thus provides a structure to interpret previous work describing the population elasticities of sectoral employment, such as Henderson (1983) and Holmes and Stevens (2004).26 The second implication, which we will refer to as the "pairwise comparisons test", says that if cities are divided into bins ordered

\footnotetext{
${ }^{25}$ The linear regression may understood as a first-order Taylor approximation: $\ln f(\nu, c) \approx \ln f\left(\nu, c^{*}\right)+$ $\frac{\partial \ln f\left(\nu, c^{*}\right)}{\partial \ln L(c)}\left(\ln L(c)-\ln L\left(c^{*}\right)\right)+\epsilon=\alpha_{\nu}+\beta_{\nu} \ln L(c)+\epsilon_{\nu, c}$, where $\beta_{\nu}=\frac{\partial \ln f\left(\nu, c^{*}\right)}{\partial \ln L(c)}$ is increasing in $\nu$ by $\log -$ supermodularity of $f(\nu, c)$.

26 Henderson (1983) regresses employment shares on population levels, but reports "percent $\Delta$ share / percent $\Delta$ population", which is equal to $\beta_{\sigma}-1$ in our notation. Similarly, Holmes and Stevens (2004) describe how location quotients, a city's share of industry employment divided by its share of total employment, vary with city size. In our notation, a location quotient is $L Q(\sigma, c)=\frac{f(\sigma, c) / \sum_{c^{\prime}} f\left(\sigma, c^{\prime}\right)}{L(c) / L}$, so the $L(c)$-elasticity of $L Q(\sigma, c)$ is $\beta_{\sigma}-1$.
} 
by population sizes, then in any pairwise comparison of two bins and two skills/sectors, the bin containing more populous cities will have relatively more of the more skilled type. ${ }^{27}$

\subsection{Skills}

Following a large literature, we use observed educational attainment as a proxy for individuals skills 28 Educational attainment is a coarse measure, but it is the best measure available in data describing a large number of people across detailed geographic locations. To describe cities' skill distributions, we aggregate individual-level microdata to the level of metropolitan statistical areas (MSAs). A large literature in urban economics describes variation in terms of two skill groups, typically college and non-college workers. Following Acemoglu and Autor (2011), we use a minimum of three skill groups. The Census 2000 microdata identify 16 levels of educational attainment, from "no schooling completed" to "doctoral degree". We define three skill groups of approximately equal size among the working population: highschool degree or less; some college or associate's degree; and bachelor's degree or more. In a more ambitious approach, we also consider nine skill groups, ranging from individuals who never reached high school (3 percent of the population) to those with doctoral degrees (1 percent). ${ }^{29}$ Table 1 shows the population shares of each of these skill groups in 2000 .

Table 1: Skill groups by educational attainment

\begin{tabular}{|l|c|l|c|}
\hline Skill (3 groups) & Population share & Skill (9 groups) & Population share \\
\hline High school or less & \multirow{2}{*}{0.35} & Less than high school & 0.03 \\
& & High school dropout & 0.07 \\
& & High school graduate & 0.24 \\
\hline Some college & \multirow{2}{*}{0.32} & College dropout & 0.24 \\
& & Associate's degree & 0.08 \\
\hline BA or more & \multirow{2}{*}{0.33} & Bachelor's degree & 0.21 \\
& & Master's degree & 0.08 \\
& & Professional degree & 0.03 \\
& & Doctoral degree & 0.01 \\
\hline
\end{tabular}

Population shares are percentages of full-time, full-year prime-age workers.

Source: Census 2000 microdata via IPUMS-USA

\subsection{Sectors}

In our model, workers produce freely traded sectoral outputs indexed by $\sigma$ that are used to produce the final good. In the international trade literature, it is common to interpret

\footnotetext{
${ }^{27}$ The pairwise comparisons test follows from taking sums twice of each side of $f(\nu, c) f\left(\nu^{\prime}, c^{\prime}\right) \geq$ $f\left(\nu^{\prime}, c\right) f\left(\nu, c^{\prime}\right)$ given $c>c^{\prime} \forall c \in C \forall c^{\prime} \in C^{\prime} \forall \nu>\nu^{\prime}$.

${ }_{28}$ Costinot and Vogel (2010) show that log-supermodularity of factor supplies in an observed characteristic and unobserved skill $\omega$ is sufficient for mapping a theory with a continuum of skills to data with discrete characteristics.

${ }^{29}$ Individuals with doctorates typically earn less than individuals with professional degrees, so it may be inappropriate to treat $\mathrm{PhDs}$ as higher- $\omega$ individuals than professionals.
} 
sectors in models of comparative advantage as industries. Recent work in both international and labor economics has emphasized a perspective focused on workers completing tasks, which empirical work has frequently operationalized as occupations (Grossman and RossiHansberg, 2008; Acemoglu and Autor, 2011). We will implement empirical tests using each. We define sectors to be the 21 manufacturing industries in the three-digit stratum of the North American Industry Classification System (NAICS) or the 22 occupational categories in the two-digit stratum of the Standard Occupational Classification (SOC). We suspect that the assignment of workers to sectors is better characterized as assignments to occupations than assignments to industries, since virtually all industries employ both skilled and unskilled workers. Our measures of cross-sectoral variation in skill intensities in the following section are consistent with this conjecture.

We measure industrial employment in a metropolitan area using data from the 2000 County Business Patterns. We measure occupational employment in a metropolitan area using estimates from the 2000 BLS Occupational Employment Statistics. See appendix C for details.

\subsection{Skill intensities}

Our theory makes the strong assumption that $H(\omega, \sigma)$ is strictly log-supermodular so that sectors are ordered with respect to their skill intensities. In our empirical work, we infer sectors' skill intensities from the data using the observable characteristics of the workers employed in them. We use microdata from the 2000 Census of Population, which contains information about workers' educational attainments, industries, and occupations. We use the average years of schooling of workers employed in a sector as a measure of its skill intensity ${ }^{30}$ In doing so, we control for spatial differences by regressing years of schooling on both sectoral and city fixed effects, but we have found that omitting the city fixed effects has little effect on the estimated skill intensities. Table 2 reports the five least skill-intensive and five most skill-intensive sectors among both the 21 manufacturing industries and the 22 occupational categories. There is considerably greater variation in average years of schooling across occupational categories than across industries.31 This may suggest that the "assignment to occupations" interpretation of our model will be a more apt description of the data than the "assignments to industries" interpretation.

\footnotetext{
30 Autor and Dorn (2012) rank occupations by their skill level according to their mean log wage. Our assumption of absolute advantage is consistent with such an approach. Using average log wages as our measure of skill intensity yields empirical success rates comparable to and slightly higher on average than those reported in section 5. We use years of schooling rather than wages as our measure of sectoral skill intensities since nominal wages may also reflect compensating differentials or local amenities.

${ }^{31}$ The standard deviations of average years of schooling across occupational categories, industries, and manufacturing industries are 2.2, 1.0, and 0.9, respectively.
} 
Table 2: Sectoral skill intensities

\begin{tabular}{|clc|clc|}
\hline SOC & Occupational category & $\begin{array}{c}\text { Skill } \\
\text { intensity }\end{array}$ & NAICS & Manufacturing industry & $\begin{array}{c}\text { Skill } \\
\text { intensity }\end{array}$ \\
\hline 45 & Farming, Fishing, and Forestry & 9.3 & 315 & Apparel & 10.7 \\
37 & Building \& Grounds Cleaning & 10.9 & 314 & Textile Product Mills & 11.4 \\
35 & Food Preparation and Serving & 11.4 & 316 & Leather and Allied Product & 11.7 \\
47 & Construction and Extraction & 11.5 & 313 & Textile Mills & 11.7 \\
51 & Production & 11.6 & 337 & Furniture and Related Products & 11.7 \\
\hline 29 & Healthcare Practitioners and Technical & 15.6 & 312 & Beverage and Tobacco Products & 13.1 \\
21 & Community and Social Services & 15.8 & 336 & Transportation Equipment & 13.2 \\
25 & Education, Training, and Library & 16.5 & 324 & Petroleum and Coal Products & 13.5 \\
19 & Life, Physical, and Social Science & 17.1 & 334 & Computer \& Electronic Products & 14.1 \\
23 & Legal & 17.3 & 325 & Chemical & 14.1 \\
\hline
\end{tabular}

Source: Census 2000 microdata via IPUMS-USA.

\subsection{Pairwise weights}

The most disaggregate implications of Propositions 1 and 2 are inequalities describing the number of individuals residing (employed) in two cities and two skill groups (sectors). Empirically testing these pairwise predictions involves evaluating as many as ten million of these inequalities and summarizing the results. An important question is whether each of these comparisons should be considered equally informative.

An unweighted summary statistic assigns equal weight to correctly predicting that Chicago (population 9 million) is relatively more skilled than Des Moines (population 456 thousand) and correctly predicting that Des Moines is relatively more skilled than Kalamazoo (population 453 thousand). Given the numerous idiosyncratic features of the real world omitted from our parsimonious theory, the former comparison seems much more informative about the relevance of our theory than the latter. Similarly, an unweighted summary statistic treats comparisons involving high school graduates (24 percent of the workforce) and comparisons involving PhDs (1 percent of the workforce) equally, while these differ in their economic import.

Following Trefler (1995), we report weighted averages of success rates in addition to unweighted statistics. In describing skill distributions, we weight each pairwise comparison by the two cities' difference in log population. When we consider nine skill groups, we also report a case where we weight by the product of the two skill groups' population shares. Figure 7 shows the distribution of differences in log population across city pairs. Since the majority of city pairs have quite small differences in log population, the unweighted and weighted statistics may yield substantially different results. In describing sectoral distributions, we weight pairwise comparisons by the two cities' difference in log population, the two sectors' difference in skill intensity, or the product of these. Figure 8 shows the distribution of differences in skill intensity across occupational pairs. While not as right-skewed as the distribution of differences in log population, this distribution may cause the unweighted and weighted statistics to differ. Figure 9 shows the distribution of differences in skill intensity across industries. The median difference between occupations is 2.3 years while the median difference between manufacturing industries is only 0.9 years. This relative compression in 
skill differences in the industrial data suggests that it may prove harder to make strong statements about differences across cities in industries than in occupations. Figures 8 and 9 underscore the importance of looking at weighted comparisons.

Figure 7: Differences in population across city pairs

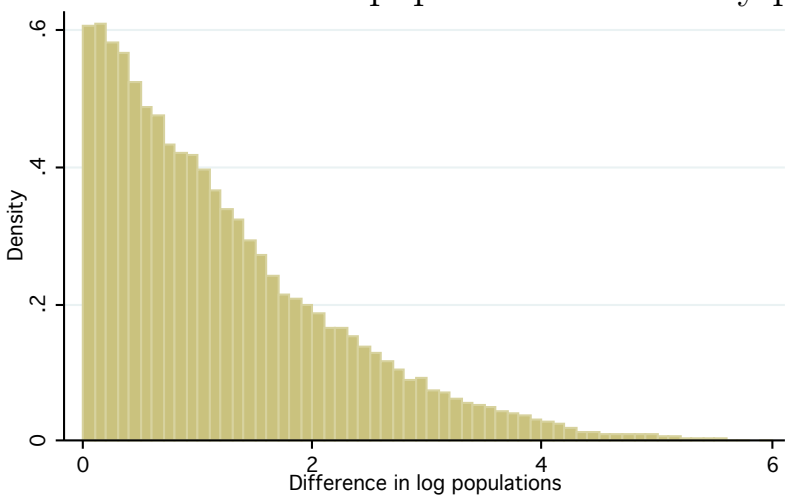

Data source: Census 2000 PHC-T-3

Figure 8: Differences in skill intensities across occupational pairs

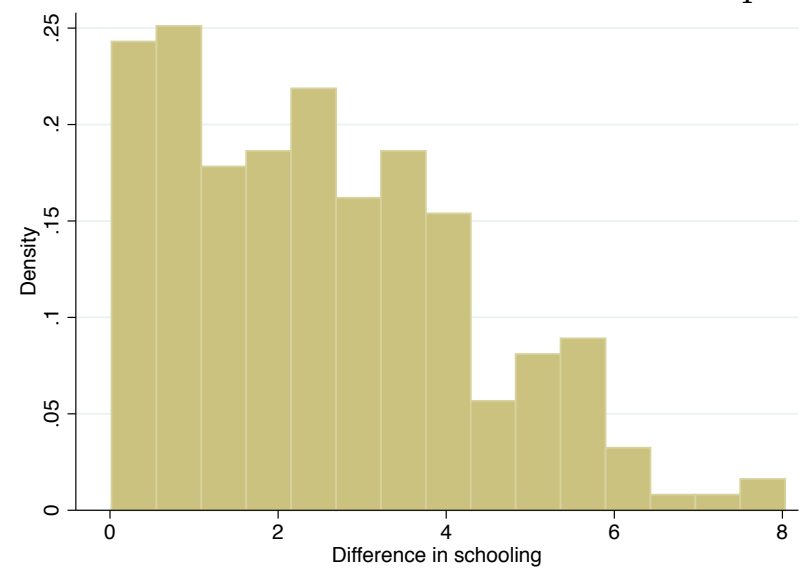

231 pairwise comparisons between 22 2-digit SOC occupational categories.

Data source: 2000 Census of Population microdata via IPUMS-USA. 
Figure 9: Differences in skill intensities across industrial pairs

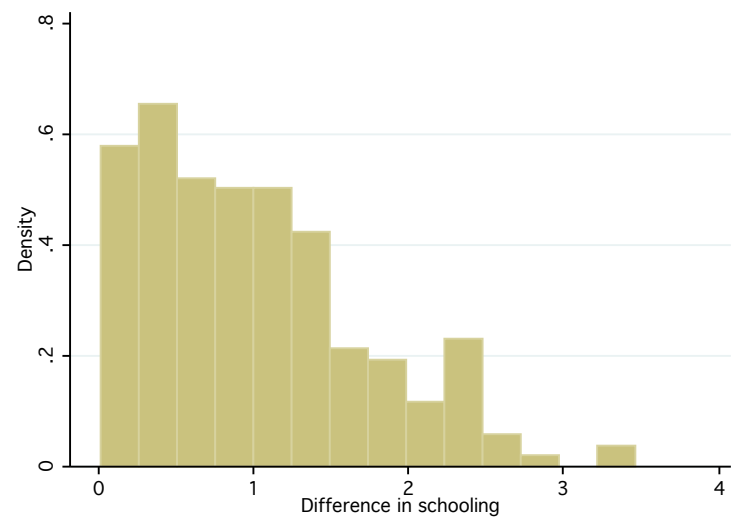

210 pairwise comparisons between 21 3-digit NAICS manufacturing industries.

Data source: 2000 Census of Population microdata via IPUMS-USA.

\section{$5 \quad$ Empirical results}

In this section, we test our predictions relating cities' sizes to their distributions of skill, occupational employment, and industrial employment. First, we examine whether populations are log-supermodular in educational attainment and city size. This prediction is a much stronger characterization of cities' skill distributions than the well known fact that larger cities typically have a greater share of college graduates. Second, we examine whether the spatial pattern of sectoral employment is governed by this spatial pattern of skills. Our theory's predictions are more realistic than completely specialized or perfectly diversified cities and more specific than theories allowing arbitrary patterns of interindustry spillovers.

The data are broadly consistent with both of our novel predictions. Skill distributions regularly exhibit the monotone likelihood ratio property, though international migration plays an important role in the largest US cities that is omitted from our model. More skillintensive sectors are relatively larger in more populous cities, on average. However, cities' sectoral distributions do not exhibit the monotone likelihood ratio property as often as cities' skill distributions do. One interpretation of this result is that skill-driven comparative advantage plays an important role in determining the spatial pattern of production, but localization and coagglomeration economies may also play a role ${ }^{32}$ We show that there are not systematic violations of our predicted pattern of comparative advantage.

\subsection{Larger cities are relatively more skilled}

This subsection tests our prediction that larger cities have relatively more skilled populations. We empirically describe skill abundance using the two tests described in section 4.1. We first do these exercises using three skill groups defined by educational attainment levels and then repeat them using nine very disaggregated skill groups.

\footnotetext{
${ }^{32}$ Since the employment data do not distinguish employees by birthplace, another possibility is that the disproportionate presence of low-skill foreign-born individuals in larger cities influences sectoral composition in a manner not described by our theory.
} 


\subsubsection{Three skill groups}

The elasticity test applied to the three skill groups across 270 metropolitan areas is reported in Table 3. The results match our theory's prediction that larger cities will have relatively more people from higher skill groups. The population elasticities are monotonically increasing in educational attainment and the elasticities differ significantly from each other. In anticipation of issues related to international immigration that arise when we examine nine skill groups, the second column of the table reports the population elasticities of US-born individuals for these three educational categories. The estimated elasticities are slightly lower, since foreign-born individuals are more concentrated in larger cities, but the differences between the elasticities are very similar.

Table 3: Population elasticities of educational groups

\begin{tabular}{|c|c|c|}
\hline Dep var: $\ln f(\omega, c)$ & All & US-born \\
\hline$\beta_{\omega_{1}}$ HS or less & 0.96 & 0.90 \\
\hline$\times \log$ population & $(0.011)$ & $(0.016)$ \\
\hline$\beta_{\omega_{2}}$ Some college & 1.00 & 0.97 \\
\hline$\times \log$ population & $(0.010)$ & $(0.012)$ \\
\hline$\beta_{\omega_{3}} \mathrm{BA}$ or more & 1.10 & 1.07 \\
\hline$\times \log$ population & $(0.015)$ & $(0.017)$ \\
\hline
\end{tabular}

Sample is all full-time, full-year employees residing in 270 metropolitan areas.

The pairwise comparison test examines ordered groups of cities to see if the relative population of the more skilled is greater in larger cities. Implementing this test involves defining groups of cities. Ordering cities by population, we partition the 270 metropolitan areas in our data into 2, 3, 5, 10,30, 90, and 270 sets of cities. Making pairwise comparisons between three skill groups and as many as 270 metropolitan areas involves computing up to 108,945 inequalities ${ }^{33}$ Note that prior work typically describes a contrast between large and small cities for high and low skills, whereas our most aggregated comparison is between large and small cities for three skill groups.

Figure 10 and Appendix Table 6 summarize the results of these tests using various sets of cities, weights, and birthplaces. In the unweighted comparisons, the success rate ranges from 60 percent when comparing individual cities to 97 percent when comparing five groups of cities to 100 percent for the standard case of two groups of cities. Weighting the comparisons by the population difference generally yields a higher success rate 34 When we weight by population differences, the success rate is 67 percent when comparing individual cities, 98 percent for five groups of cities, and 100 percent for the simple comparison of large versus small cities 35

\footnotetext{
${ }^{33}$ With $n$ city groups and $m$ skill groups, we make $\frac{n(n-1)}{2} \frac{m(m-1)}{2}$ comparisons. For example, $\frac{270 \times 269}{2} \frac{3 \times 2}{2}=$ 108,945 .

${ }^{34}$ Despite the fact that the success rate of the Des-Moines-Kalamazoo comparisons is actually higher than the Chicago-Des-Moines comparisons.

${ }^{35}$ Our comparisons of two or five groups of cities are analogous to the empirical exercises presented in Eeckhout, Pinheiro, and Schmidheiny (2011) and Bacolod, Blum, and Strange (2009).
} 
Figure 10: Pairwise comparisons of three skill groups

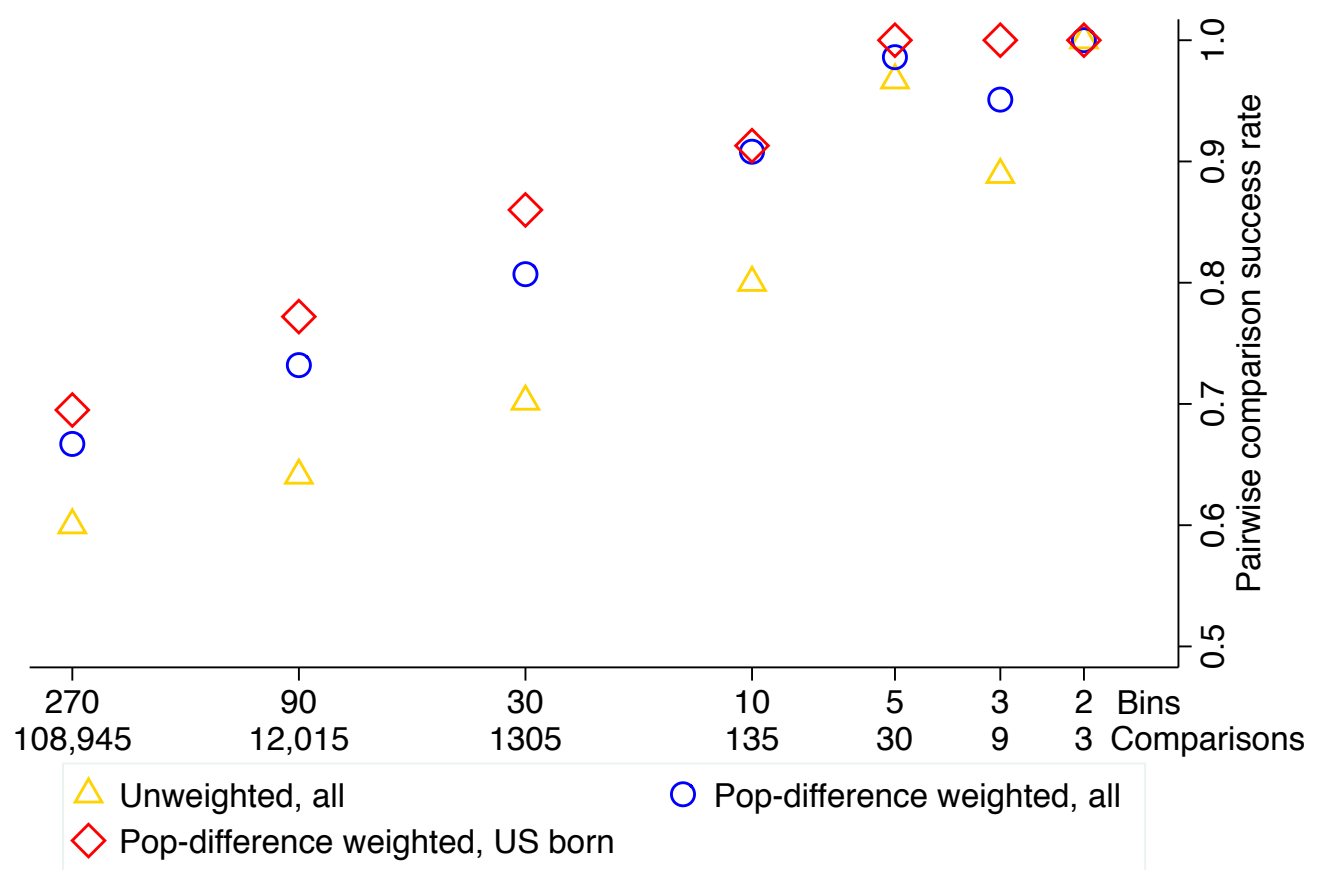

\subsubsection{Nine skill groups}

We next examine our tests for the case with nine skill groups. Starting with the elasticity test, Table 4 shows, contrary to our model's predictions, that those not completing high school are highly prevalent in larger cities. The second column reveals that this result is due to the presence of foreign-born individuals with low educational attainment in larger cities. If we restrict attention to US-born individuals, we can only reject the hypothesis that $\beta_{\omega} \geq \beta_{\omega^{\prime}} \Longleftrightarrow \omega \geq \omega^{\prime}$ in one of thirty-six comparisons, the case where $\beta_{\omega_{2}}=0.94>0.90=$ $\beta_{\omega_{3}} \sqrt{36}$ In short, the elasticity test provides strong support for our theory when we examine the US-born population ${ }^{37}$

How should we interpret the difference between the spatial distribution of skills among the population as a whole and among US-born individuals? One possibility is that immigrants strongly prefer larger cities for reasons omitted from our model, causing less-skilled foreignborn individuals to disproportionately locate in larger cities. This would be consistent with an established literature that describes agglomeration benefits particular to unskilled foreignborn individuals, such as linguistic enclaves (Edin, Fredriksson, and Aslund, 2003, Bauer, Epstein, and Gang, 2005) ${ }^{38}$

\footnotetext{
${ }^{36}$ The estimated elasticities for the tails of the skill distribution have larger standard errors. This likely reflects greater sampling noise for scarce educational categories; for example, the median (C)MSA had 34 observations of full-time, full-year employees with a $\mathrm{PhD}$ in the 5 percent public-use 2000 Census microdata.

${ }^{37}$ Interestingly, among US-born individuals, the nine estimated elasticities naturally break into the three more aggregate educational attainment categories that we used above: $\beta_{\omega_{1}}, \beta_{\omega_{2}}, \beta_{\omega_{3}} \in(0.91,0.94) ; \beta_{\omega_{4}}, \beta_{\omega_{5}} \in$ $(0.96,0.98) ; \beta_{\omega_{6}}, \beta_{\omega_{7}}, \beta_{\omega_{8}}, \beta_{\omega_{9}} \in(1.06,1.09)$.

${ }^{38}$ Another potential mechanism is that immigrants may find larger cities' combination of higher nominal wages and higher housing prices more attractive than natives (Diamond, 2012), possibly because they remit
} 
Table 4: Population elasticities of educational groups, 2000

\begin{tabular}{|l|cc|}
\hline \multicolumn{1}{|c}{ Dep var: $\ln f(\omega, c)$} & All & US-born \\
\hline$\beta_{\omega_{1}}$ Less than HS & 1.17 & 0.91 \\
$\times$ log population & $(0.039)$ & $(0.028)$ \\
$\beta_{\omega_{2}}$ High school dropout & 1.03 & 0.94 \\
$\times$ log population & $(0.017)$ & $(0.020)$ \\
$\beta_{\omega_{3}}$ High school graduate & 0.93 & 0.90 \\
$\times$ log population & $(0.013)$ & $(0.016)$ \\
$\beta_{\omega_{4}}$ College dropout & 1.00 & 0.98 \\
$\times$ log population & $(0.011)$ & $(0.013)$ \\
$\beta_{\omega_{5}}$ Associate's degree & 1.00 & 0.96 \\
$\times \log$ population & $(0.014)$ & $(0.016)$ \\
$\beta_{\omega_{6}}$ Bachelor's degree & 1.10 & 1.07 \\
$\times$ log population & $(0.015)$ & $(0.017)$ \\
$\beta_{\omega_{7}}$ Master's degree & 1.12 & 1.09 \\
$\times$ log population & $(0.018)$ & $(0.019)$ \\
$\beta_{\omega_{8}}$ Professional degree & 1.12 & 1.09 \\
$\times$ log population & $(0.018)$ & $(0.019)$ \\
$\beta_{\omega_{9}}$ PhD & 1.11 & 1.06 \\
$\times$ log population & $(0.035)$ & $(0.033)$ \\
\hline
\end{tabular}

Standard errors, clustered by MSA, in parentheses.

Sample is all full-time, full-year employees residing in 270 metropolitan areas.

Eeckhout, Pinheiro, and Schmidheiny (2011) articulate another possibility, in which an economic mechanism they term "extreme-skill complementarity" causes less skilled individuals, foreign-born or US-born, to disproportionately reside in larger cities. Larger cities' benefits for immigrants serve as a "tie breaker" that causes the foreign-born to choose larger cities in equilibrium. This theory predicts that in the absence of foreign-born low-skilled individuals, US-born low-skilled individuals would disproportionately locate in larger cities.

We attempt to distinguish between these hypotheses by looking at the skill distributions of US cities two decades earlier. In 2000, foreign-born individuals were 11 percent of the US population, while in 1980 they constituted about 6 percent. More importantly, in 2000, foreign-born individuals constituted nearly 80 percent of the lowest skill group, while in 1980 they were less than one third of the lowest skill group. If our hypothesis that foreignborn individuals are particularly attracted to larger cities is correct, then the population elasticity of less-skilled types should be lower when foreign-born shares are lower. Table 5 demonstrates that this is the case in 1980. It does not provide any evidence that the least skilled were overrepresented in larger cities in 1980, among either the population as a whole or US-born individuals. ${ }^{39}$ Reconciling these results with the model of Eeckhout, Pinheiro, and Schmidheiny (2011) would require that the production function changed from top-skill

their nominal incomes abroad or demand less housing than US-born individuals.

${ }^{39}$ The educational categories in Table 5 differ from prior tables because Census microdata collected prior to 1990 identify coarser levels of educational attainment in terms of years of schooling rather than highest degree attained. 
Table 5: Population elasticities of educational groups, 1980

\begin{tabular}{|c|c|c|c|}
\hline & $\begin{array}{l}\text { opulatio } \\
\text { share }\end{array}$ & All & US-born \\
\hline $\begin{array}{c}\beta_{\omega_{1}} \text { Less than grade } 9 \\
\times \log \text { population }\end{array}$ & 0.06 & $\begin{array}{r}0.99 \\
(0.028)\end{array}$ & $\begin{array}{c}0.89 \\
(0.030)\end{array}$ \\
\hline $\begin{array}{l}\beta_{\omega_{2}} \text { Grades } 9-11 \\
\quad \times \log \text { population }\end{array}$ & 0.11 & $\begin{array}{c}1.00 \\
(0.019)\end{array}$ & $\begin{array}{c}0.98 \\
(0.021)\end{array}$ \\
\hline $\begin{array}{l}\beta_{\omega_{3}} \text { Grade } 12 \\
\times \log \text { population }\end{array}$ & 0.33 & $\begin{array}{c}0.97 \\
(0.013)\end{array}$ & $\begin{array}{c}0.95 \\
(0.015)\end{array}$ \\
\hline $\begin{array}{l}\beta_{\omega_{4}} 1 \text { year college } \\
\quad \times \log \text { population }\end{array}$ & 0.08 & $\begin{array}{c}1.04 \\
(0.018)\end{array}$ & $\begin{array}{c}1.03 \\
(0.018)\end{array}$ \\
\hline $\begin{array}{c}\beta_{\omega_{5}} 2-3 \text { years college } \\
\times \log \text { population }\end{array}$ & 0.13 & $\begin{array}{c}1.09 \\
(0.018)\end{array}$ & $\begin{array}{c}1.07 \\
(0.018)\end{array}$ \\
\hline $\begin{array}{l}\beta_{\omega_{6}} 4 \text { years college } \\
\quad \times \log \text { population }\end{array}$ & 0.13 & $\begin{array}{c}1.10 \\
(0.018)\end{array}$ & $\begin{array}{c}1.08 \\
(0.018)\end{array}$ \\
\hline $\begin{array}{l}\beta_{\omega_{7}} 5+\text { years college } \\
\quad \times \log \text { population }\end{array}$ & 0.13 & $\begin{array}{c}1.13 \\
(0.022)\end{array}$ & $\begin{array}{c}1.11 \\
(0.022)\end{array}$ \\
\hline
\end{tabular}

Standard errors, clustered by MSA, in parentheses

Sample is all full-time, full-year employees residing in 253 metropolitan areas.

complementarity in 1980 to extreme-skill complementarity in 2000.

We now turn to the pairwise comparisons for the case with nine skill groups in 2000, summarized in Figure 11 and Appendix Table 7. These test inequalities for 36,315 individual city pairs for each pairing of the nine skill groups. In both the unweighted and weighted comparisons, our theory does best in predicting comparisons of skill groups that have a high school degree or higher attainment. Fewer than 50 percent of the comparisons yield the correct inequality when the "less than high school" skill group is involved in the comparison. As would be expected from the previous results, these comparisons are considerably more successful when restricted to the US-born population. When these are also weighted by population differences and education shares, the overall success rate in comparing individual cities rises to 64 percent.

Figure 11 and Appendix Table 8 show how the pairwise comparison success varies when we group cities by size. When we restrict attention to the US-born, the unweighted success rate respectively for individual cities, five and two groups of cities are 56 percent, 71 percent, and 81 percent. If, in addition, we weight successes by education shares and population differences, the success rates for individual cities, five and two groups of cities are 64 percent, 87 percent, and 88 percent, respectively. In short, for the case of nine skill groups, the raw comparisons for individual cities including the foreign born show very modest success. As in the elasticities test, restricting attention to the US-born population yields significant improvement. Likewise, there is considerably greater success as we group cities and as we weight them by the overall prevalence of the education group in the labor force. Overall, we consider this solid support for our theory. 
Figure 11: Pairwise comparisons of nine skill groups

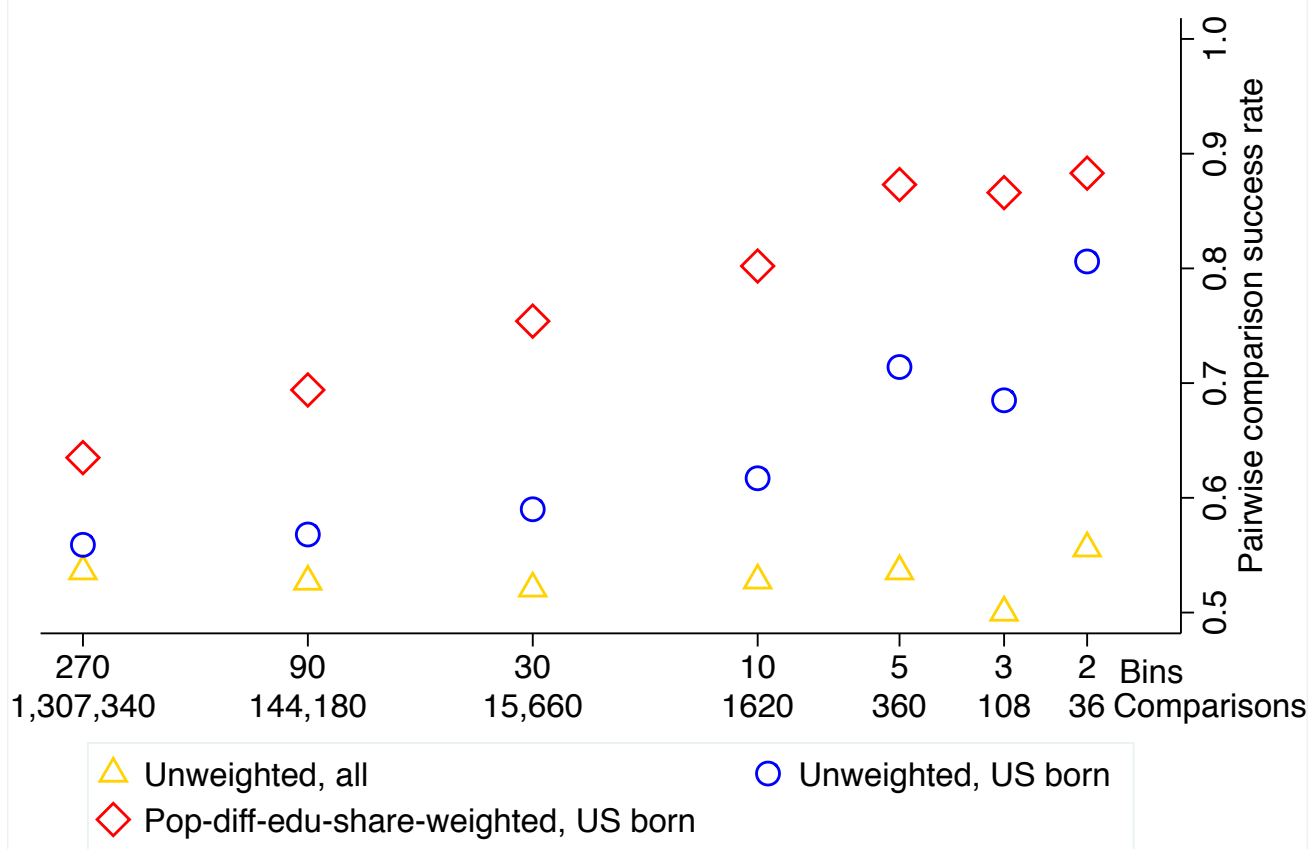

\subsection{Larger cities specialize in skill-intensive sectors}

This section examines the spatial pattern of sectoral employment. In our theory, larger cities are relatively more skilled, cities' equilibrium productivity differences are Hicks-neutral, and sectors can be ordered by their skill intensity, so larger cities employ relatively more labor in skill-intensive sectors. We established that larger cities are relatively more skilled in section 5.1. We now examine whether larger cities are relatively specialized in skill-intensive sectors. Since employment levels in both industries and occupations are readily available in the data, we test the employment implications of Proposition $2{ }^{40}$

\subsubsection{The spatial distribution of occupations}

We first implement the elasticities test and the pairwise comparisons test interpreting sectors as occupations. We begin with a visualization of the elasticity data. Figure 12 plots the 22 occupational categories' estimated population elasticities of employment against their skill intensities, measured as the average years of schooling of individuals employed in that occupation 41 There is a clear positive relationship. Outliers in the figure include close-tounitary elasticities for the relatively skilled occupations in education, healthcare, and social services, which may reflect non-traded status. On the other side, computer and mathematical occupations have an elasticity that is quite high relative to their average schooling.

\footnotetext{
${ }^{40}$ Section 5.1 showed that US-born individuals better match our model's predictions about the distribution of skills. Unfortunately, the County Business Patterns and Occupational Employment Statistics data describe employment counts, not individual employees' characteristics, so we cannot address the birthplace issues in this section.

${ }^{41}$ These elasticities are estimated without including zero-employment observations. The results obtained when including those observations are similar.
} 
Figure 12: Occupations' population elasticities and skill intensities

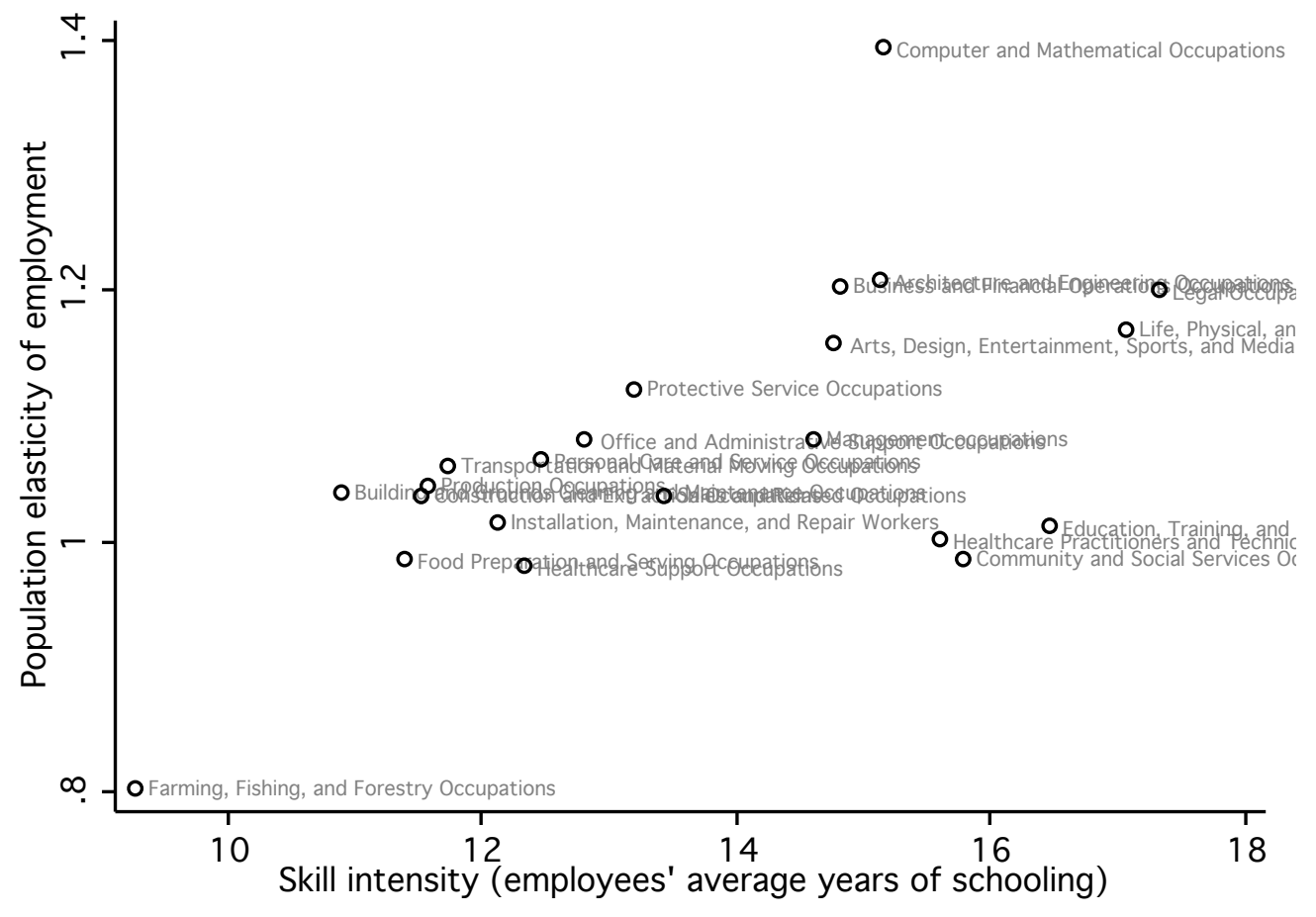

We can also look at this more formally. With the population elasticities of occupations in hand, the hypothesis that $\beta_{\sigma} \geq \beta_{\sigma^{\prime}} \Longleftrightarrow \sigma \geq \sigma^{\prime}$ involves $231(=22 \times 21 / 2)$ comparisons of the estimated coefficients 42 This hypothesis is rejected at the five-percent significance level in 46 comparisons, so the success rate is 80 percent.

The results for pairwise comparisons for occupations appear in Figure 13 and Appendix Table 10. When we do this for 276 cities and 22 occupations, we have a total of 8,766,450 pairwise comparisons, of which 53 percent are correct. This is low compared to our results for skills. When we stay with individual cities but weight by population and skill differences, this rises above 58 percent. We can maintain the weighting and consider it for cities grouped by size into, for example, 30,5 , or 2 groups. The corresponding proportion of successes rises respectively to 66,73 , and 78 percent. While the results for occupations are not as strong as the results for skills, there are nonetheless quite informative patterns - even when we group cities into five size-based bins, we get nearly three-fourths of the pairwise comparisons correct across the 22 occupational categories.

\footnotetext{
${ }^{42}$ The elasticity estimates appear in Appendix Table 9
} 
Figure 13: Pairwise comparisons of 22 occupational categories

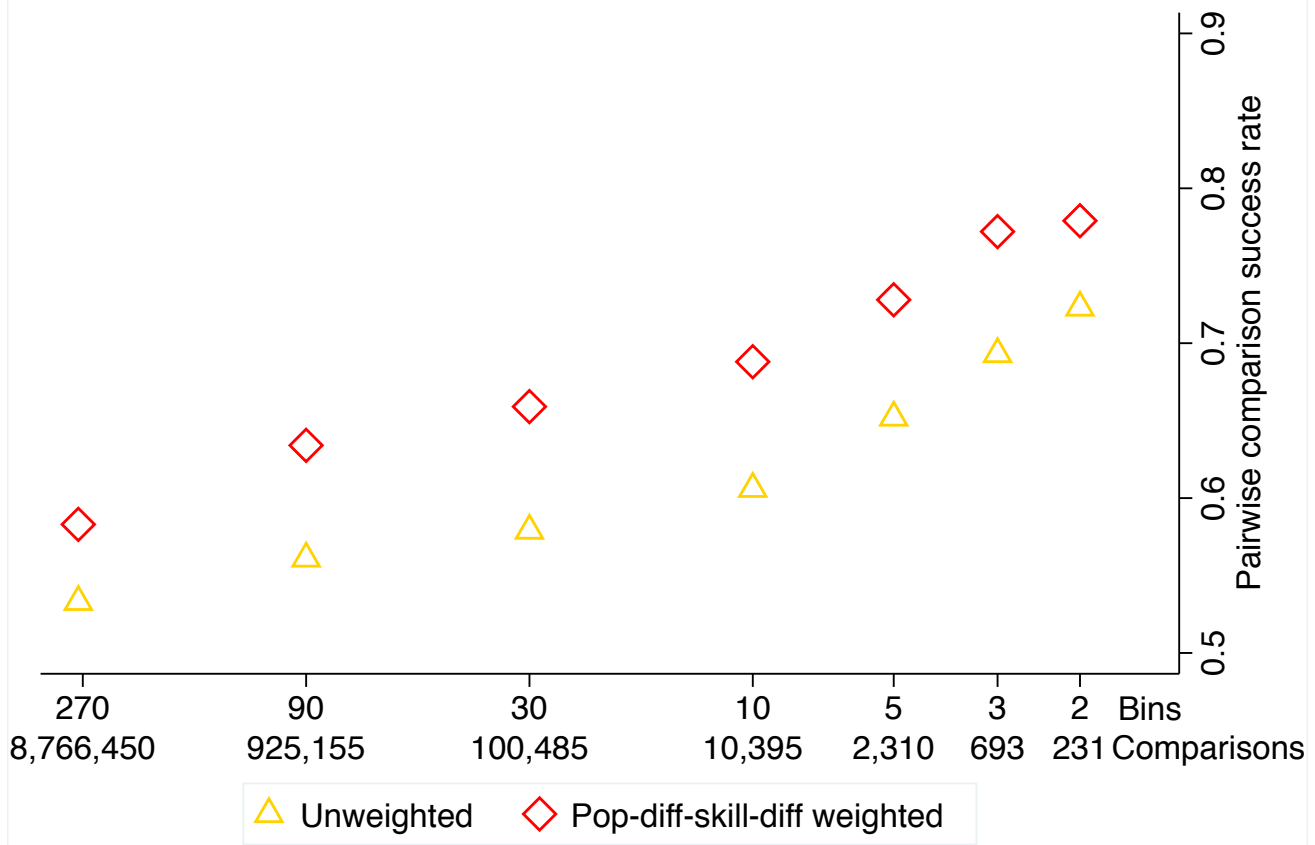

\subsubsection{The spatial distribution of industries}

We now implement the elasticities test and the pairwise comparisons test interpreting sectors as manufacturing industries ${ }^{43}$ A visualization of the elasticity test appears in Figure 14. Again, as predicted by our theory, there is a clear positive relationship so that the population elasticity of industry employment is rising with the skill intensity of the industry. The apparel industry is an outlier, with low average education and a high population elasticity of employment. This may reflect the share of apparel industry employees who are lessskilled foreign-born individuals, consistent with our previous discussion of skills. Testing the hypothesis that $\beta_{\sigma} \geq \beta_{\sigma^{\prime}} \Longleftrightarrow \sigma \geq \sigma^{\prime}$ for the 21 manufacturing industries involves 210 $(=21 \times 20 / 2)$ comparisons of these estimated elasticities ${ }^{44}$ This hypothesis is rejected in 26 comparisons, so the elasticity implication holds true for manufacturing industries about 87 percent of the time ${ }^{45}$ This success rate is higher than the corresponding statistic for occupational elasticities.

The pairwise comparisons results for industries appear in Figure 15 and Appendix Table 12. When we do this for 276 individual cities and 21 industries, we have a total of nearly 8 million pairwise comparisons, of which just half are correct. Weighting this by skill and population differences raises this to 54 percent, again low compared to our results for pairwise comparisons of skills. We can maintain the weighting and consider this for cities grouped by

\footnotetext{
${ }^{43}$ We focus on manufacturing industries since we believe they have the lowest trade costs, but we have found broadly similar results when using all industries.

${ }^{44}$ The elasticity estimates appear in Appendix Table 11.

${ }^{45}$ If we restrict the data to uncensored observations, which reduces the sample considerably, this hypothesis is rejected in 32 comparisons, for an 85 percent success rate. See appendix C for a discussion of censoring in County Business Patterns data.
} 
Figure 14: Industries' population elasticities and skill intensities

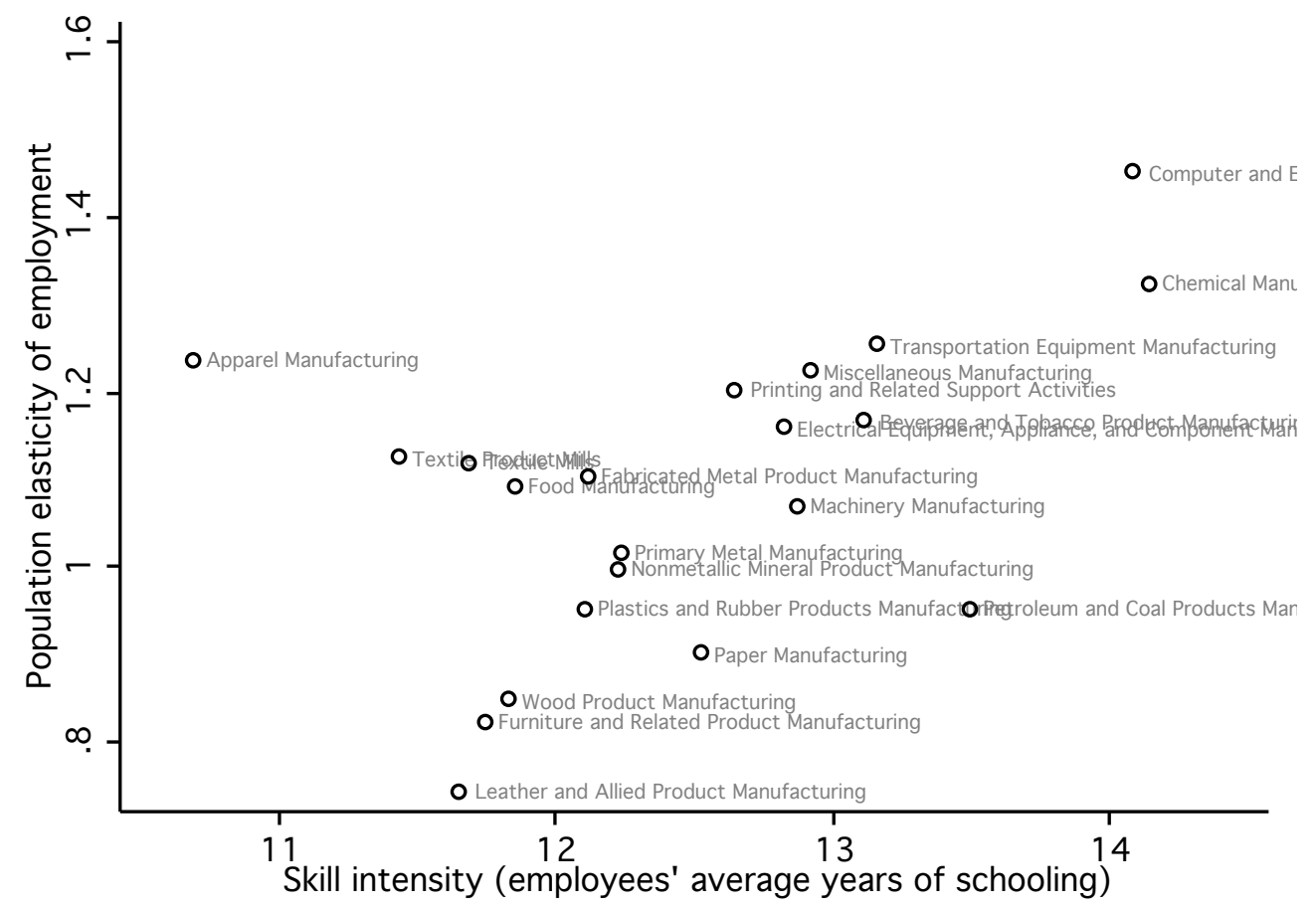

size into 30, 5, or 2 groups. The corresponding proportion of successes rises respectively to 58, 66, and 71 percent. These are low relative to the prior results on occupations and even more so relative to the results on skills. Nonetheless, they do show that there is systematic variation across cities of different sizes in the composition of manufacturing 46 Note that prior work contrasting large and medium-size cities, Henderson (1997), is analogous to our comparisons of two or three groups of cities ordered by population.

\footnotetext{
${ }^{46}$ These results are not driven solely by the largest metropolitan areas; excluding the ten largest cities from pairwise comparisons of occupations and industries yields similar success rates.
} 
Figure 15: Pairwise comparisons of 21 manufacturing industries

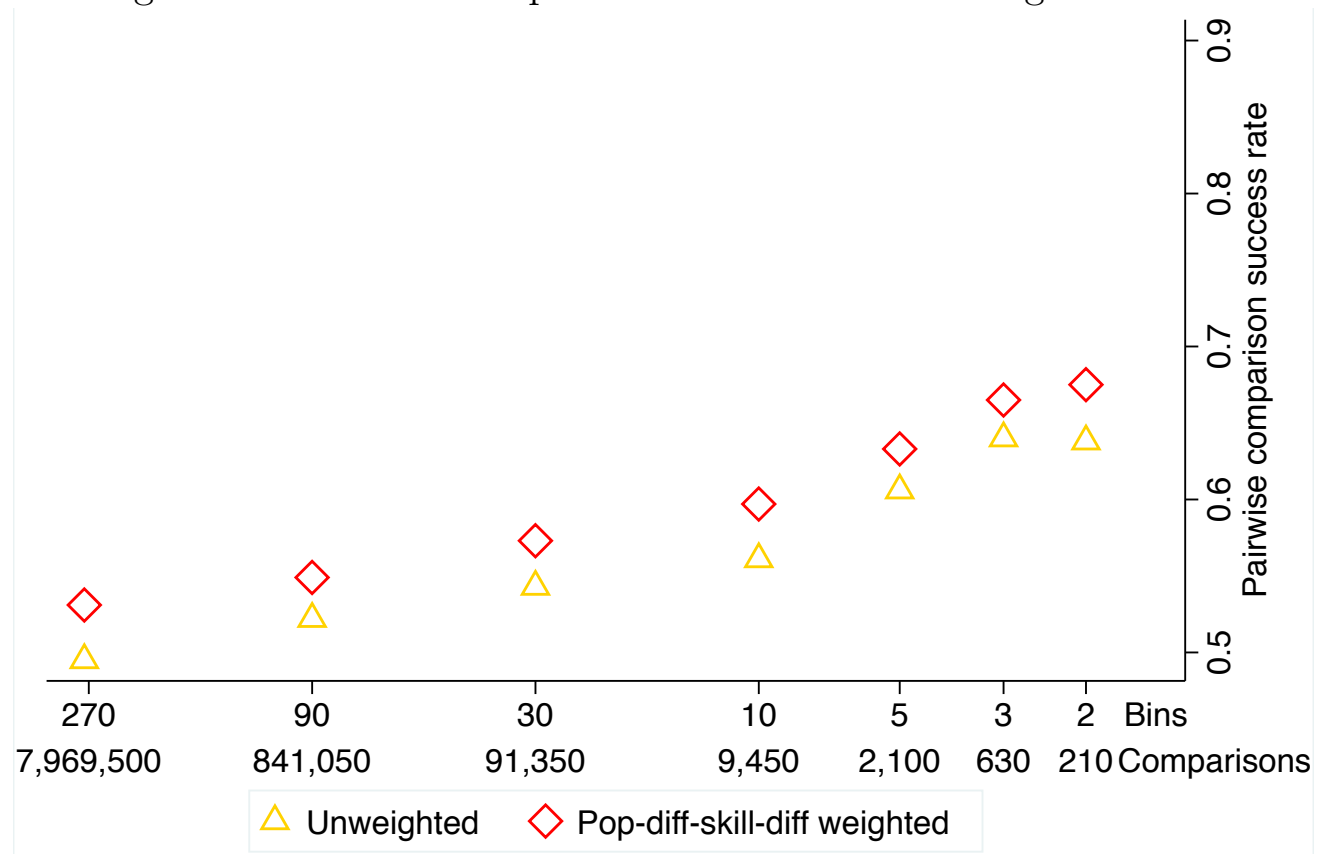

\subsection{Testing for systematic failures of comparative advantage}

Our results for the cross-city distributions of skills, industries, and occupations demonstrate systematic patterns in line with our theory's predictions. While demonstrating predictive power, the pairwise comparisons also reveal that we fall well short of 100 percent success. This is not surprising, given that our model's parsimony stems from making strong assumptions that omit various features that influence the real world. An important question is whether our theory's unsuccessful pairwise predictions are merely idiosyncratic deviations from the pattern of comparative advantage or are systematic violations of our predicted pattern.

Sattinger (1978) develops an approach to test for such systematic violations in the form of systematic intransitivity in the pattern of comparative advantage. It is possible for the data to exhibit, for $c>c^{\prime}>c^{\prime \prime}$ and $\sigma>\sigma^{\prime}>\sigma^{\prime \prime}, \frac{f(\sigma, c)}{f\left(\sigma^{\prime}, c\right)} \geq \frac{f\left(\sigma, c^{\prime}\right)}{f\left(\sigma^{\prime}, c^{\prime}\right)}$ and $\frac{f\left(\sigma^{\prime}, c^{\prime}\right)}{f\left(\sigma^{\prime \prime}, c^{\prime}\right)} \geq \frac{f\left(\sigma^{\prime}, c^{\prime \prime}\right)}{f\left(\sigma^{\prime \prime}, c^{\prime \prime}\right)}$ without exhibiting $\frac{f(\sigma, c)}{f\left(\sigma^{\prime \prime}, c\right)} \geq \frac{f\left(\sigma, c^{\prime \prime}\right)}{f\left(\sigma^{\prime \prime}, c^{\prime \prime}\right)}$. With hundreds of metropolitan areas and dozens of sectors, it is easy to find three cities and three sectors in the data exhibiting such intransitivity. But does intransitive comparative advantage arise systematically? Sattinger (1978) shows that if $\ln f(\sigma, c)$ is a polynomial function of $\hat{\beta}_{\sigma}$ and $\ln$ population $_{c}$, then there can be systematic intransitivity only if $\ln f(\sigma, c)$ is a function of higher-order interactions of $\hat{\beta}_{\sigma}$ and $\ln$ population $_{c}$. We therefore added quadratic terms and their interactions to our elasticity regressions. These did little to improve the regression's adjusted $R^{2}$, and F-tests yielded p-values that did not come close to rejecting the null that these additional terms were uninformative. There is no evidence of systematic intransitivity in comparative advantage. While our theory's predictive successes are systematic, the empirical departures from our theory appear to be idiosyncratic. 


\section{Discussion and conclusions}

In this paper, we introduce a model that simultaneously characterizes the distribution of skills and sectors across cities. We describe a high-dimensional economic environment that is a system of cities in which cities' internal geographies exhibit substantive heterogeneity and individuals' comparative advantage governs the distribution of sectoral employment. Our model achieves two aims. First, we obtain "smooth" predictions, in the sense that cities' skill and sectoral distributions will be highly overlapping. These are more realistic than prior theories describing cities that are perfectly sorted along skills or polarized in terms of sectoral composition. Second, we obtain "strong" predictions, in the sense that cities' skill and sectoral distributions will exhibit systematic variation according to the monotone likelihood ratio property. These are more precise than the predictions of many prior theories of the spatial organization of economy activity and guide our empirical investigation.

Examining data on US metropolitan areas' populations, occupations, and industries in the year 2000 reveals systematic variation in the cross-city distribution of skills and sectors that is consistent with our theory. Larger cities are skill abundant. Our results using three equal-sized categories of educational attainment are quite strong. Even disaggregated to nine educational categories, the cross-city distribution of US-born individuals is well described by our theory.

Empirically, we find that larger cities specialize in skill-intensive activities. More skillintensive occupations and industries tend to have higher population elasticities of employment. In making pairwise comparisons, our model does better in describing the pattern of occupational employment than industrial employment. This is consistent with a recent emphasis in the literature on workers performing tasks. Our results demonstrate that metropolitan skill distributions shape the comparative advantage of cities, though the fact that our sectoral-employment predictions are not as strong as our skill-distribution predictions is consistent with the idea that localization or coagglomeration economies omitted from our model may also be important.

We believe that our framework is amenable to both theoretical and empirical applications and extensions. The "smoothness" resulting from the simultaneous consideration of crossand within-city heterogeneity in a continuum-by-continuum environment would make our model amenable to theoretical analyses of the consequences of commuting costs, globalization, and skill-biased technical change. The "strong" character of our predictions and their demonstrated relevance for describing US cities in 2000 suggest that their examination in other settings, such as economies at different stages of development or in different historical periods, would be interesting. 


\section{References}

Abdel-Rahman, H. M., and A. Anas (2004): "Theories of systems of cities," in Handbook of Regional and Urban Economics, ed. by J. V. Henderson, and J. F. Thisse, vol. 4, chap. 52, pp. 2293-2339. Elsevier. 5, 6, 7

Acemoglu, D., and D. Autor (2011): "Skills, Tasks and Technologies: Implications for Employment and Earnings," in Handbook of Labor Economics, ed. by O. Ashenfelter, and D. Card, vol. 4, pp. 1043-1171. Elsevier. 6, 19, 20

Autor, D., And D. Dorn (2012): "The Growth of Low Skill Service Jobs and the Polarization of the U.S. Labor Market," IZA Discussion Papers 7068, Institute for the Study of Labor (IZA). 20

Bacolod, M., B. S. Blum, and W. C. Strange (2009): "Skills in the city," Journal of Urban Economics, 65(2), 136-153. 24

Bagnoli, M., and T. Bergstrom (2005): "Log-concave probability and its applications," Economic Theory, 26(2), 445-469. 15

Bauer, T., G. Epstein, and I. Gang (2005): "Enclaves, language, and the location choice of migrants," Journal of Population Economics, 18(4), 649-662. 25

Baum-Snow, N., And R. Pavan (2011): "Inequality and City Size," mimeo. 6]

Behrens, K., G. Duranton, and F. Robert-Nicoud (2010): "Productive cities: Sorting, selection and agglomeration," CEPR Discussion Paper 7922. 5, 6

Bernstein, J. R., And D. E. Weinstein (2002): "Do endowments predict the location of production?: Evidence from national and international data," Journal of International Economics, 56(1), 55-76. 7

Brueckner, J. K. (1987): "The structure of urban equilibria: A unified treatment of the muth-mills model," in Handbook of Regional and Urban Economics, ed. by E. S. Mills, vol. 2, chap. 20, pp. 821-845. Elsevier. 6

Christaller, W. (1933): Die zentralen Orte in Suddeutschland. Gustav Fischer, Jena. 7

Costinot, A. (2009): "An Elementary Theory of Comparative Advantage," Econometrica, $77(4), 1165-1192.4,5,6,17$

Costinot, A., And J. Vogel (2010): "Matching and Inequality in the World Economy," Journal of Political Economy, 118(4), 747-786. 4, 6, 11, 17, 19, 38

Davis, D. R., And J. I. Dingel (2012): "A Spatial Knowledge Economy," NBER Working Papers 18188, National Bureau of Economic Research, Inc. 5, 6]

Davis, D. R., And D. E. Weinstein (1999): "Economic geography and regional production structure: An empirical investigation," European Economic Review, 43(2), 379-407. 7 
Diamond, R. (2012): “The Determinants and Welfare Implications of US Workers' Diverging Location Choices by Skill: 1980-2000," mimeo. 25

Duranton, G., and H. G. Overman (2005): "Testing for Localization Using MicroGeographic Data," Review of Economic Studies, 72(4), 1077-1106. 7

Duranton, G., And D. Puga (2001): "Nursery Cities: Urban Diversity, Process Innovation, and the Life Cycle of Products," American Economic Review, 91(5), 1454-1477. 5

Edin, P.-A., P. Fredriksson, and O. Aslund (2003): "Ethnic Enclaves and the Economic Success of Immigrants - Evidence from a Natural Experiment," The Quarterly Journal of Economics, 118(1), 329-357. 25

Eeckhout, J., R. Pinheiro, and K. Schmidheiny (2011): "Spatial Sorting," Discussion paper. 5, 24, 25, 26,

Ellison, G., and E. L. Glaeser (1997): "Geographic Concentration in U.S. Manufacturing Industries: A Dartboard Approach," Journal of Political Economy, 105(5), 889-927. 7

Ellison, G., E. L. Glaeser, And W. R. Kerr (2010): "What Causes Industry Agglomeration? Evidence from Coagglomeration Patterns," American Economic Review, 100(3), 1195-1213. 7

Fajgelbaum, P., G. M. Grossman, and E. Helpman (2011): "Income Distribution, Product Quality, and International Trade," Journal of Political Economy, 119(4), 721 765. 37

Fujita, M., And J.-F. Thisse (2002): Economics of Agglomeration. Cambridge University Press. 4, 6

Glaeser, E. L. (2008): Cities, Agglomeration, and Spatial Equilibrium, The Lindahl Lectures. Oxford University Press. 6

Grossman, G. M., and E. Rossi-Hansberg (2008): "Trading Tasks: A Simple Theory of Offshoring," American Economic Review, 98(5), 1978-97. 20

Helsley, R. W., And W. C. Strange (1990): "Matching and agglomeration economies in a system of cities," Regional Science and Urban Economics, 20(2), 189-212. 5

— (2012): "Coagglomeration and the Scale and Composition of Clusters," UC Berkeley mimeo. 4, 7, 8

Henderson, J. V. (1974): "The Sizes and Types of Cities," American Economic Review, 64(4), 640-56. 8

164-68. 8, 18 
(1987): "General equilibrium modeling of systems of cities," in Handbook of Regional and Urban Economics, ed. by E. S. Mills, vol. 2, chap. 23, pp. 927-956. Elsevier. 8

8

(1991): Urban Development: Theory, Fact, and Illusion. Oxford University Press.

Henderson, V. (1997): "Medium size cities," Regional Science and Urban Economics, 27(6), 583-612. 8, 31

Hendricks, L. (2011): "The Skill Composition Of U.S. Cities," International Economic Review, 52(1), 1-32. 6

Holmes, T. J., And J. J. Stevens (2004): "Spatial distribution of economic activities in North America," in Handbook of Regional and Urban Economics, ed. by J. V. Henderson, and J. F. Thisse, vol. 4, chap. 63, pp. 2797-2843. Elsevier. 7, 18

Hsu, W.-T., T. J. Holmes, and F. Morgan (2013): "Optimal City Hierarchy: A Dynamic Programming Approach to Central Place Theory," mimeo. 7

Leamer, E. E. (1984): Sources of International Comparative Advantage: Theory and Evidence. MIT Press. 7

LeRoy, S. F., And J. Sonstelie (1983): "Paradise lost and regained: Transportation innovation, income, and residential location," Journal of Urban Economics, 13(1), 67-89. 6]

LuCAS, R. E. (1988): "On the mechanics of economic development," Journal of Monetary Economics, 22(1), 3-42. 8

Lucas, R. E., And E. Rossi-Hansberg (2002): "On the Internal Structure of Cities," Econometrica, 70(4), 1445-1476. 6

Ruggles, S., J. T. Alexander, K. Genadek, R. Goeken, M. B. Schroeder, And M. SobeK (2010): "Integrated Public Use Microdata Series: Version 5.0 [Machinereadable database]," Minneapolis, MN: Minnesota Population Center. 40

Samuelson, P. A. (1948): "International trade and the equalisation of factor prices," The Economic Journal, 58(230), 163-184. 6]

Sattinger, M. (1975): "Comparative Advantage and the Distributions of Earnings and Abilities," Econometrica, 43(3), 455-68. 4

- (1978): "Comparative Advantage in Individuals," The Review of Economics and Statistics, 60(2), 259-67. 32

(1979): "Differential Rents and the Distribution of Earnings," Oxford Economic Papers, 31(1), 60-71. 4. 6

(1993): "Assignment Models of the Distribution of Earnings," Journal of Economic Literature, 31(2), 831-80. 6 
Trefler, D. (1995): "The Case of the Missing Trade and Other Mysteries," American Economic Review, 85(5), 1029-46. 21

von Thünen, J. H. (1826): Der Isolierte Staat in Beziehung auf Landschaft und Nationalökonomie. 6

\section{A Appendix: Consumption interpretation}

The production and consumption interpretations yield very similar results but differ slightly in notation. In the consumption interpretation, an individual's productivity and utility are

$$
\begin{aligned}
q(c, \delta, \sigma ; \omega) & =A(c) H(\omega, \sigma) \\
U(\omega, c, \delta, \sigma) & =D(\delta)[A(c) H(\omega, \sigma) p(\sigma)-r(c, \delta)]
\end{aligned}
$$

where $D(\delta)$ determines the value of the individual's disposable income after paying his or her locational price ${ }^{47}$ In this interpretation, preferences are non-homothetic in a manner akin to that of Fajgelbaum, Grossman, and Helpman (2011). Higher-income individuals are more willing to pay for higher-quality locations because a more desirable location complements their higher consumption of tradables.

In this case, instead of $\gamma=A(c) D(\delta)=A\left(c^{\prime}\right) D\left(\delta^{\prime}\right) \Longleftrightarrow r(c, \delta)=r\left(c^{\prime}, \delta^{\prime}\right)=r_{\Gamma}(\gamma)$, the appropriate equivalence between two locations is their "amenity-inclusive price", which is $D(\delta) r(c, \delta)$. So the equivalence statement is now $\gamma=A(c) D(\delta)=A\left(c^{\prime}\right) D\left(\delta^{\prime}\right) \Longleftrightarrow$ $D(\delta) r(c, \delta)=D\left(\delta^{\prime}\right) r\left(c^{\prime}, \delta^{\prime}\right)=r_{\Gamma}(\gamma)$. The results in lemma 1 are unaltered, though the proof is modified to use the relevant $U(\omega, c, \delta, \sigma)$. The expressions for $K: \Gamma \rightarrow \Omega, \bar{\gamma}$, and $\gamma$ are unaltered. This leaves the conclusions of lemmas 4, 5, and 6 intact. The locational price schedule is given by $r(c, \delta)=\frac{r_{\Gamma}(A(c) D(\delta))}{D(\delta)}$.

These locational prices do not appear in the proof of Proposition 1 nor the endogenous definition of $A(c)$. When evaluated at equilibrium, occupied locations' productivities $q(c, \delta, \sigma ; \omega)=A(c) H(\omega, \sigma)$ differ across cities in a Hicks-neutral fashion that satisfies Costinot's Definition 4 (see footnote 23), so Proposition 2 applies. As a result, the predictions about cities' population, sectors, and productivities described in sections 3.5 and 3.6 are unaltered by interpreting $D(\delta)$ as describing consumption benefits rather than production benefits.

\section{B Appendix: Proofs}

Proof of Lemma 1;

Proof. Suppose that $\exists \delta^{\prime}<\bar{\delta}(c): \quad S\left(\delta^{\prime}\right)>L \int_{0}^{\delta^{\prime}} \int_{\sigma \in \Sigma} \int_{\omega \in \Omega} f(\omega, c, x) d \omega d \sigma d x$. Then $\exists \delta \leq$ $\delta^{\prime}: S^{\prime}(\delta)>L \int_{\sigma \in \Sigma} \int_{\omega \in \Omega} f(\omega, c, \delta) d \omega d \sigma$. Then $\left.r(c, \delta)\right)=0 \leq r(c, \bar{\delta}(c))$, so $U(\omega, c, \delta, \sigma)>$ $U(\omega, c, \bar{\delta}(c), \sigma) \forall \omega \forall \sigma$ since $D(\delta)$ is strictly decreasing. This contradicts the definition of $\bar{\delta}(c)$, since $\bar{\delta}(c)$ is a location that maximizes utility for some individual. Therefore $S(\delta)=$ $L \int_{0}^{\delta} \int_{\sigma \in \Sigma} \int_{\omega \in \Omega} f(\omega, c, x) d \omega d \sigma d x \forall \delta \leq \bar{\delta}(c)$.

\footnotetext{
${ }^{47}$ Recall that the final good is the numeraire.
} 
Suppose that $\exists \delta^{\prime}, \delta^{\prime \prime}: \delta^{\prime}<\delta^{\prime \prime} \leq \bar{\delta}(c)$ and $r\left(c, \delta^{\prime}\right) \leq r\left(c, \delta^{\prime \prime}\right)$. Then $U\left(\omega, c, \delta^{\prime}, \sigma\right)>$ $U\left(\omega, c, \delta^{\prime \prime}, \sigma\right) \forall \omega \forall \sigma$ since $D(\delta)$ is strictly decreasing. This contradicts the result that $\delta^{\prime \prime}$ maximizes utility for some individual. Therefore $r(c, \delta)$ is strictly decreasing in $\delta \forall \delta \leq \bar{\delta}(c)$.

Suppose $r(c, \bar{\delta}(c))>0$. Then by its definition as a populated location, $\exists \omega: A(c) D(\bar{\delta}(c)) G(\omega)-$ $r(c, \bar{\delta}(c)) \geq A(c) D(\bar{\delta}(c)+\epsilon) G(\omega) \forall \epsilon>0$. This inequality is false for all $\omega$ for sufficiently small $\epsilon$, by the continuity of $D(\delta)$. Therefore $r(c, \bar{\delta}(c))=0$.

Proof of Lemma 2 :

Proof. Our argument follows the proof of Lemma 1 in Costinot and Vogel (2010). Define $f(\omega, c, \delta) \equiv \int_{\sigma \in \Sigma} f(\omega, c, \delta, \sigma) d \sigma$. Define $\Omega(\delta) \equiv\{\delta \in \Delta \mid f(\omega, c, \delta)>0\}$ and $\Delta(\omega) \equiv\{\omega \in$ $\Omega \mid f(\omega, c, \delta)>0\}$.

1. $\Delta(\omega) \neq \emptyset$ by equation 11 and $f(\omega)>0 . \Omega(\delta) \neq \emptyset \forall \delta \leq \bar{\delta}(c)$ by lemma 1

2. $\Omega(\delta)$ is a non-empty interval. For $\delta<\delta^{\prime}$, if $\omega \in \Omega(\delta)$ and $\omega^{\prime} \in \Omega\left(\delta^{\prime}\right)$, then $\omega \geq \omega^{\prime}$. Suppose $\omega<\omega^{\prime}<\omega^{\prime \prime}$ with $\omega, \omega^{\prime \prime} \in \Omega(\delta)$ and $\omega^{\prime} \notin \Omega(\delta) . \quad \exists \delta^{\prime}: \omega^{\prime} \in \Omega\left(\delta^{\prime}\right)$. Suppose $\delta^{\prime}>\delta$. By utility maximization

$$
\begin{aligned}
A(c) D\left(\delta^{\prime}\right) G\left(\omega^{\prime}\right)-r\left(c, \delta^{\prime}\right) & \geq A(c) D(\delta) G\left(\omega^{\prime}\right)-r(c, \delta) \\
A(c) D(\delta) G(\omega)-r(c, \delta) & \geq A(c) D\left(\delta^{\prime}\right) G(\omega)-r\left(c, \delta^{\prime}\right)
\end{aligned}
$$

These jointly imply $\left(D\left(\delta^{\prime}\right)-D(\delta)\right)\left(G\left(\omega^{\prime}\right)-G(\omega)\right) \geq 0$, contrary to $\delta^{\prime}>\delta$ and $\omega^{\prime}>\omega$. The $\delta^{\prime}<\delta$ case is analogous, using $\omega^{\prime}$ and $\omega^{\prime \prime}$. Therefore $\Omega(\delta)$ is a non-empty interval. The same pair of inequalities proves that for $\delta<\delta^{\prime}$, if $\omega \in \Omega(\delta)$ and $\omega^{\prime} \in \Omega\left(\delta^{\prime}\right)$, then $\omega \geq \omega^{\prime}$.

3. $\Omega(\delta)$ is singleton for all but a countable subset of $\Delta$. Follow Costinot and Vogel (2010).

4. $\Delta(\omega)$ is singleton for all but a countable subset of $\Omega$. Follow Costinot and Vogel (2010).

5. $\Omega(\delta)$ is singleton. Follow Costinot and Vogel (2010).

Step 5 means there is a function $N: \Delta \rightarrow \Omega$ such that $f(\omega, c, \delta)>0 \Longleftrightarrow N(\delta)=\omega$. Step 2 says $N$ is weakly decreasing. Since $\Omega(\delta) \neq \emptyset, N$ is continuous and satisfies $N(0)=\bar{\omega}$ and $N(\bar{\delta}(c))=\underline{\omega}$. Step 4 means that $N$ is strictly decreasing.

Proof of the explicit expression of $N(\delta)$ that follows Lemma 2 .

$$
\begin{aligned}
S(\delta) & =L \int_{0}^{\delta} \int_{\sigma \in \Sigma} \int_{\omega \in \Omega} f(\omega, c, x, \sigma) d \omega d \sigma d x \\
& =L \int_{0}^{\delta} \int_{\omega \in \Omega} f(\omega) \delta^{\text {Dirac }}\left[x-N^{-1}(\omega)\right] d \omega d x \\
& =L \int_{0}^{\delta} \int_{\delta^{\prime}} f\left(N\left(\delta^{\prime}\right)\right) \delta^{\text {Dirac }}\left[x-\delta^{\prime}\right] N^{\prime}\left(\delta^{\prime}\right) d \delta^{\prime} d x \\
& =-L \int_{0}^{\delta} f(N(x)) N^{\prime}(x) d x=L(1-F(N(\delta))) \\
\Rightarrow N(\delta) & =F^{-1}\left(\frac{L-S(\delta)}{L}\right)
\end{aligned}
$$




\section{Proof of Lemma 3 .}

Proof. By utility maximization

$$
\begin{aligned}
A(c) D(\delta) G(N(\delta))-r(c, \delta) & \geq A(c) D(\delta+d \delta) G(N(\delta))-r(c, \delta+d \delta) \\
A(c) D(\delta+d \delta) G(N(\delta+d \delta))-r(c, \delta+d \delta) & \geq A(c) D(\delta) G(N(\delta+d \delta))-r(c, \delta)
\end{aligned}
$$

Together, these inequalities imply

$$
\begin{array}{r}
\frac{A(c) D(\delta+d \delta) G(N(\delta))-A(c) D(\delta) G(N(\delta))}{d \delta} \leq \frac{r(c, \delta+d \delta)-r(c, \delta)}{d \delta} \\
\leq \frac{A(c) D(\delta+d \delta) G(N(\delta+d \delta))-A(c) D(\delta) G(N(\delta+d \delta))}{d \delta}
\end{array}
$$

Taking the limit as $d \delta \rightarrow 0$, we obtain $\frac{\partial r(c, \delta)}{\partial \delta}=A(c) D^{\prime}(\delta) G(N(\delta))$. Integrating from $\delta$ to $\bar{\delta}(c)$ and using the boundary condition $r(c, \bar{\delta}(c))=0$ yields $r(c, \delta)=-A(c) \int_{\delta}^{\bar{\delta}(c)} D^{\prime}(t) G(N(t)) d t$.

Proof of Lemma 4;

[This proof is analogous to the proof of lemma 2.]

Proof of Lemma 5 .

Proof. By utility maximization

$$
\begin{aligned}
\gamma G(K(\gamma))-r_{\Gamma}(\gamma) & \geq(\gamma+d \gamma) G(K(\gamma))-r_{\Gamma}(\gamma+d \gamma) \\
(\gamma+d \gamma) G(K(\gamma+d \gamma))-r_{\Gamma}(\gamma+d \gamma) & \geq \gamma G(K(\gamma+d \gamma))-r_{\Gamma}(\gamma)
\end{aligned}
$$

Together, these inequalities imply

$$
\frac{(\gamma+d \gamma) G(K(\gamma+d \gamma))-\gamma G(K(\gamma+d \gamma))}{d \gamma} \geq \frac{r_{\Gamma}(\gamma+d \gamma)-r_{\Gamma}(\gamma)}{d \gamma} \geq \frac{(\gamma+d \gamma) G(K(\gamma))-\gamma G(K(\gamma))}{d \gamma}
$$

Taking the limit as $d \gamma \rightarrow 0$, we obtain $\frac{\partial r_{\Gamma}(\gamma)}{\partial \gamma}=G(K(\gamma))$. Integrating from $\underline{\gamma}$ to $\gamma$ and using the boundary condition $r_{\Gamma}(\gamma)=0$ yields $r_{\Gamma}(\gamma)=\int_{\underline{\gamma}}^{\gamma} G(K(x)) d x$.

Proof of Lemma 6:

Proof. In city $c$, the population of individuals with skills between $\omega$ and $\omega+d \omega$ is

$$
L \int_{\omega}^{\omega+d \omega} f(x, c) d x=S\left(D^{-1}\left(\frac{K^{-1}(\omega)}{A(c)}\right)\right)-S\left(D^{-1}\left(\frac{K^{-1}(\omega+d \omega)}{A(c)}\right)\right)
$$

Taking the derivative with respect to $d \omega$ and then taking the limit as $d \omega \rightarrow 0$ yields the population of $\omega$ in $c$.

In the course of proving Proposition 1, we use the following lemma.

Lemma 7. Let $f(z), g(x), h(y): \mathbb{R}^{+} \rightarrow \mathbb{R}^{++}$be $C^{1}$ functions with $g^{\prime}(x)>0 \forall x$ and $h^{\prime}(y)>$ $0 \forall y$. If $f(z)$ is decreasing and log-concave, then $f\left(\frac{g(x)}{h(y)}\right)$ is log-supermodular in $x$ and $y$. 
Proof. $f\left(\frac{g(x)}{h(y)}\right)$ is log-supermodular in $x$ and $y$ if and only if

$$
\frac{\partial^{2} \ln f(g(x) / h(y))}{\partial x \partial y}=\left.\frac{g^{\prime} h^{\prime}}{h^{2}}\left(-\frac{\partial}{\partial z}\left(z \frac{\partial \ln f(z)}{\partial z}\right)\right)\right|_{z=g(x) / h(y)} \geq 0 .
$$

If $f(z)$ is decreasing and log-concave, then $\frac{\partial}{\partial z}\left(z \frac{\partial \ln f(z)}{\partial z}\right) \leq 0 \forall z \geq 0$, so $f\left(\frac{g(x)}{h(y)}\right)$ is $\log$ supermodular.

Proof of Proposition 1 .

Proof. The population of skill $\omega$ in city $c$ can be written as

$$
f(\omega, c)=-\frac{1}{L} \frac{\partial}{\partial \omega} S\left(D^{-1}\left(\frac{K^{-1}(\omega)}{A(c)}\right)\right)=\frac{K^{-1^{\prime}}(\omega)}{A(c) L}\left[\left.\left(-\frac{\partial}{\partial z} S\left(D^{-1}(z)\right)\right)\right|_{z=\frac{K^{-1}(\omega)}{A(c)}}\right]
$$

Since $\frac{K^{-1^{\prime}}(\omega)}{A(c) L}$ is multiplicatively separable in $\omega$ and $c, f(\omega, c)$ is log-supermodular if and only if the term in brackets is log-supermodular. Since $K^{-1}(\omega)$ and $A(c)$ are increasing functions, if $-\frac{\partial}{\partial z} S\left(D^{-1}(z)\right)$ is a decreasing and log-concave function, then $f(\omega, c)$ is $\log$ supermodular by lemma 7 .

\section{Appendix: Data}

Data sources: Our metropolitan population data are from the US Census website (2000). Our data on individuals' demographics, educational attainments, geographic locations, and sectors of employment come from the 5 percent sample of the 2000 US Census and the 1 percent metro sample of the 1980 US Census made available by IPUMS-USA (Ruggles, Alexander, Genadek, Goeken, Schroeder, and Sobek, 2010). Our data on industrial employment come from the 2000 County Business Patterns, available from the US Census Bureau website. Our data on occupational employment come from the 2000 Occupational Employment Statistics, available from the Burea of Labor Statistics website.

Geography: We use (consolidated) metropolitan statistical areas as defined by the OMB as our unit of analysis.

The smallest geographic unit in the IPUMS-USA microdata is the public-use microdata area (PUMA), which has a minimum of 100,000 residents. We map the PUMAs to metropolitan statistical areas (MSAs) using the MABLE Geocorr2K geographic correspondence engine from the Missouri Census Data Center. In some sparsely populated areas, a PUMA is larger than a metropolitan area. We drop six MSAs in which fewer than half of the residents of the only relevant PUMA live within the metropolitan area. As a result, there are 270 MSAs when we use Census of Population data.

The 1980 Census of Population IPUMS-USA microdata do not identify PUMAs, so we use the "metarea" variable describing 253 consolidated MSAs for the regressions in Table 5 .

The County Business Patterns data describe 318 metropolitan statistical areas. These correspond to a mix of OMB-defined primary and consolidated metropolitan statistical areas outside New England and New England county metropolitan areas (NECMAs). We 
aggregate these into OMB-defined (consolidated) metropolitan statistical areas to obtain 276 MSAs.

The Occupational Employment Statistics data describe 331 (primary) metropolitan statistical areas. We aggregate these into OMB-defined (consolidated) metropolitan statistical areas to obtain observations for 276 MSAs.

Skill distribution: Our sample of individuals includes all full-time, full-year prime-age workers, defined as individuals 25 to 55 years of age who reported working at least 35 hour per week and 40 weeks in the previous year. Using the 'educd' variable from IPUMS, we construct nine levels of educational attainment: less than high school, high school dropout, high school graduate, some college, associate's degree, bachelor's degree, master's degree, professional degree, and doctorate. There is at least one observation in every educational category in every metropolitan area.

Sectoral skill intensity: Using the same sample of full-time, full-year prime-age workers, we measure a sector's skill intensity by calculating the average years of schooling of its employees after controlling for spatial differences in average schooling. We calculate years of schooling using the educational attainment "educd" variable from IPUMS at its finest level of disaggregation. For instance, this means that we distinguish between those whose highest educational attainment is sixth grade or eighth grade. We use the "indnaics' and 'occsoc' variables to assign individuals to their 3-digit NAICS and 2-digit SOC sectors of employment. Aggregating observations to the MSA-sector level, weighted by the IPUMS-provided person weights, we regress the average years of schooling on MSA and sectoral dummies. The sectoral dummy coefficients are our measure of skill intensities.

Industrial employment: There 963 -digit NAICS industries, of which 21 are manufacturing industries. 75 of these industries, including all 21 manufacturing industries, appear in both the Census of Population microdata and the County Business Patterns data. The County Business Patterns data are an almost exhaustive account of US employer establishments. When necessary to protect the confidentiality of individual establishments, employment in an industry in a location is reported as falling within an interval rather than its exact number. In our empirical work, we use the midpoints of these intervals as the level of employment. There are 390 (C)MSA-manufacturing-industry pairs, out of $5796=21 \times 276$, in which there are zero establishments. The County Business Patterns data omit self-employed individuals and employees of private households, railroads, agriculture production, the postal service, and public administrations. See the CBP methodology webpage for details.

Occupational employment: There are 22 2-digit SOC occupations. Across 331 (P)MSAs, there should be 7282 metropolitan-occupation observations. The 2000 BLS Occupational Employment Statistics contain employment estimates for 7129 metropolitan-occupation observations, none of which are zero. The 153 omitted observations "may be withheld from publication for a number of reasons, including failure to meet BLS quality standards or the need to protect the confidentiality of [BLS] survey respondents." 31 of these observations are for "farming occupations", and the vast majority of them are for less populous metropolitan areas. We assign these observations values of zero when they are included in our calculations.

\section{Appendix: Tables}


Table 6: Pairwise comparisons of three skill groups

\begin{tabular}{|ccc|c|c|c|c|c|}
\hline Bins & Weights & Birthplace & $\begin{array}{c}\text { College vs } \\
\text { some college }\end{array}$ & $\begin{array}{c}\text { College vs } \\
\text { HS or less }\end{array}$ & $\begin{array}{c}\text { Some college } \\
\text { vs HS or less }\end{array}$ & $\begin{array}{c}\text { Total } \\
\text { comparisons }\end{array}$ & Average \\
\hline 2 & Unweighted & All & 1.00 & 1.00 & 1.00 & 3 & 1.00 \\
2 & Pop diff & All & 1.00 & 1.00 & 1.00 & 3 & 1.00 \\
2 & Unweighted & US-born & 1.00 & 1.00 & 1.00 & 3 & 1.00 \\
2 & Pop diff & US-born & 1.00 & 1.00 & 1.00 & 3 & 1.00 \\
\hline 3 & Unweighted & All & 1.00 & 1.00 & .667 & 9 & .889 \\
3 & Pop diff & All & 1.00 & 1.00 & .853 & 9 & .951 \\
3 & Unweighted & US-born & 1.00 & 1.00 & 1.00 & 9 & 1.00 \\
3 & Pop diff & US-born & 1.00 & 1.00 & 1.00 & 9 & 1.00 \\
\hline 5 & Unweighted & All & 1.00 & 1.00 & .900 & 30 & .967 \\
5 & Pop diff & All & 1.00 & 1.00 & .959 & 30 & .986 \\
5 & Unweighted & US-born & 1.00 & 1.00 & 1.00 & 30 & 1.00 \\
5 & Pop diff & US-born & 1.00 & 1.00 & 1.00 & 30 & 1.00 \\
\hline 10 & Unweighted & All & .800 & .844 & .756 & 135 & .8 \\
10 & Pop diff & All & .914 & .935 & .875 & 135 & .908 \\
10 & Unweighted & US-born & .800 & .867 & .756 & 135 & .808 \\
10 & Pop diff & US-born & .914 & .951 & .875 & 135 & .913 \\
\hline 30 & Unweighted & All & .763 & .717 & .625 & 1,305 & .702 \\
30 & Pop diff & All & .875 & .845 & .699 & 1,305 & .806 \\
30 & Unweighted & US-born & .775 & .759 & .699 & 1,305 & .744 \\
30 & Pop diff & US-born & .886 & .878 & .817 & 1,305 & .86 \\
\hline 90 & Unweighted & All & .671 & .666 & .587 & 12,015 & .641 \\
90 & Pop diff & All & .788 & .774 & .634 & 12,015 & .732 \\
90 & Unweighted & US-born & .672 & .686 & .639 & 12,015 & .666 \\
90 & Pop diff & US-born & .790 & .800 & .727 & 12,015 & .772 \\
\hline 270 & Unweighted & All & .629 & .616 & .556 & 108,945 & .6 \\
270 & Pop diff & All & .717 & .695 & .588 & 108,945 & .667 \\
270 & Unweighted & US-born & .624 & .635 & .589 & 108,945 & .616 \\
270 & Pop diff & US-born & .712 & .726 & .647 & 108,945 & .695 \\
\hline
\end{tabular}


Table 7: Pairwise comparisons of nine skill groups with one city per bin

\begin{tabular}{|c|c|c|c|c|c|c|c|c|c|}
\hline \multicolumn{10}{|c|}{ Unweighted comparisons } \\
\hline & & LHS & HSD & HS & CD & $\mathrm{AA}$ & $\mathrm{BA}$ & MA & Pro \\
\hline 2 & HSD & .423 & & & & & & & \\
\hline 3 & HS & .399 & .413 & & & & & & \\
\hline 4 & CD & .428 & .486 & .587 & & & & & \\
\hline 5 & AA & .43 & .483 & .571 & .483 & & & & \\
\hline 6 & BA & .476 & .555 & .644 & 619 & .602 & & & \\
\hline 7 & MA & .484 & .558 & .643 & .614 & .615 & .528 & & \\
\hline 8 & Pro & .484 & .57 & .645 & .617 & .604 & .524 & .499 & \\
\hline 9 & $\mathrm{PhD}$ & .49 & .548 & .598 & .576 & .577 & .521 & .501 & .511 \\
\hline \multicolumn{10}{|c|}{ Population-difference weighted comparisons of US-born population } \\
\hline & & LHS & HSD & HS & $\mathrm{CD}$ & $\mathrm{AA}$ & $\mathrm{BA}$ & MA & Pro \\
\hline 2 & HSD & .568 & & & & & & & \\
\hline 3 & HS & .488 & .435 & & & & & & \\
\hline 4 & CD & .583 & .569 & .649 & & & & & \\
\hline 5 & $\mathrm{AA}$ & .552 & .53 & .616 & .453 & & & & \\
\hline 6 & BA & .644 & .65 & .738 & .695 & .682 & & & \\
\hline 7 & MA & .648 & .651 & .738 & .686 & .695 & .544 & & \\
\hline 8 & Pro & .654 & .654 & .73 & .676 & .676 & .533 & .493 & \\
\hline 9 & $\mathrm{PhD}$ & .611 & .605 & .651 & .605 & .617 & .502 & .476 & .497 \\
\hline
\end{tabular}


Table 8: Pairwise comparisons of nine skill groups

\begin{tabular}{|clccc|}
\hline Bins & Weights & $\begin{array}{c}\text { Total } \\
\text { comparisons }\end{array}$ & $\begin{array}{c}\text { All individuals } \\
\text { success rate }\end{array}$ & $\begin{array}{c}\text { US-born } \\
\text { success rate }\end{array}$ \\
\hline 2 & Unweighted & 36 & .556 & .806 \\
2 & Population differences & 36 & .556 & .806 \\
2 & Educational shares & 36 & .754 & .883 \\
2 & Pop diff $\times$ edu shares & 36 & .754 & .883 \\
3 & Unweighted & 108 & .5 & .685 \\
3 & Population differences & 108 & .54 & .744 \\
3 & Educational shares & 108 & .707 & .836 \\
3 & Pop diff $\times$ edu shares & 108 & .736 & .866 \\
5 & Unweighted & 360 & .536 & .714 \\
5 & Population differences & 360 & .55 & .767 \\
5 & Educational shares & 360 & .747 & .844 \\
5 & Pop diff $\times$ edu shares & 360 & .756 & .873 \\
10 & Unweighted & 1620 & .528 & .617 \\
10 & Population differences & 1620 & .551 & .696 \\
10 & Educational shares & 1620 & .67 & .715 \\
10 & Pop diff $\times$ edu shares & 1620 & .725 & .802 \\
30 & Unweighted & 15,660 & .521 & .59 \\
30 & Population differences & 15,660 & .545 & .656 \\
30 & Educational shares & 15,660 & .632 & .666 \\
30 & Pop diff $\times$ edu shares & 15,660 & .699 & .754 \\
90 & Unweighted & 144,180 & .527 & .568 \\
90 & Population differences & 144,180 & .555 & .626 \\
90 & Educational shares & 144,180 & .594 & .614 \\
90 & Pop diff $\times$ edu shares & 144,180 & .657 & .694 \\
270 & Unweighted & $1,307,340$ & .536 & .559 \\
270 & Population differences & $1,307,340$ & .564 & .605 \\
270 & Educational shares & $1,307,340$ & .567 & .579 \\
270 & Pop diff $\times$ edu shares & $1,307,340$ & .612 & .635 \\
\hline
\end{tabular}


Table 9: Occupational employment population elasticities

\begin{tabular}{|c|c|c|c|}
\hline$\beta_{\sigma_{1}}$ Farming, Fishing, and Forestry Occupations & 0.803 & $\beta_{\sigma_{12}}$ Sales and Related Occupations & 1.037 \\
\hline$\times \log$ population & $(0.048)$ & $\times \log$ population & $(0.010)$ \\
\hline$\beta_{\sigma_{2}}$ Building and Grounds Cleaning and Maintenance & 1.039 & $\beta_{\sigma_{13}}$ Management occupations & 1.082 \\
\hline$\times \log$ population & $(0.011)$ & $\times \log$ population & $(0.015)$ \\
\hline$\beta_{\sigma_{3}}$ Food Preparation and Serving Occupations & 0.985 & $\beta_{\sigma_{14}}$ Arts, Design, Entertainment, Sports, and Media & 1.158 \\
\hline$\times \log$ population & $(0.011)$ & $\times \log$ population & $(0.019)$ \\
\hline$\beta_{\sigma_{4}}$ Construction and Extraction Occupations & 1.037 & $\beta_{\sigma_{15}}$ Business and Financial Operations Occupations & 1.204 \\
\hline$\times \log$ population & $(0.014)$ & $\times \log$ population & $(0.018)$ \\
\hline$\beta_{\sigma_{5}}$ Production Occupations & 1.045 & $\beta_{\sigma_{16}}$ Architecture and Engineering Occupations & 1.209 \\
\hline$\times \log$ population & $(0.025)$ & $\times \log$ population & $(0.026)$ \\
\hline$\beta_{\sigma_{6}}$ Transportation and Material Moving Occupations & 1.061 & $\beta_{\sigma_{17}}$ Computer and Mathematical Occupations & 1.395 \\
\hline$\times \log$ population & $(0.014)$ & $\times \log$ population & $(0.034)$ \\
\hline$\beta_{\sigma_{7}}$ Installation, Maintenance, and Repair Workers & 1.015 & $\beta_{\sigma_{18}}$ Healthcare Practitioners and Technical Occupations & 1.001 \\
\hline$\times \log$ population & $(0.011)$ & $\times \log$ population & $(0.014)$ \\
\hline$\beta_{\sigma_{8}}$ Healthcare Support Occupations & 0.980 & $\beta_{\sigma_{19}}$ Community and Social Services Occupations & 0.986 \\
\hline$\times \log$ population & $(0.013)$ & $\times \log$ population & $(0.020)$ \\
\hline$\beta_{\sigma_{9}}$ Personal Care and Service Occupations & 1.065 & $\beta_{\sigma_{20}}$ Education, Training, and Library Occupations & 1.011 \\
\hline$\times \log$ population & $(0.017)$ & $\times \log$ population & $(0.017)$ \\
\hline$\beta_{\sigma_{10}}$ Office and Administrative Support Occupations & 1.081 & $\beta_{\sigma_{21}}$ Life, Physical, and Social Science Occupations & 1.170 \\
\hline$\times \log$ population & $(0.010)$ & $\times \log$ population & $(0.030)$ \\
\hline$\beta_{\sigma_{11}}$ Protective Service Occupations & 1.123 & $\beta_{\sigma_{22}}$ Legal Occupations & 1.200 \\
\hline$\times \log$ population & $(0.014)$ & $\times \log$ population & $(0.022)$ \\
\hline Observations & 5943 & Observations & 5943 \\
\hline R-squared & 0.931 & R-squared & 0.931 \\
\hline Occupation FE & Yes & Occupation FE & Yes \\
\hline
\end{tabular}

Standard errors, clustered by MSA, in parentheses

Table 10: Pairwise comparisons of occupations

\begin{tabular}{|cccc|}
\hline Bins & Weights & Comparisons & Success rate \\
\hline 2 & Unweighted & 231 & 0.723 \\
2 & popdif*skilldif & 231 & 0.779 \\
3 & Unweighted & 693 & 0.693 \\
3 & popdif*skilldif & 693 & 0.772 \\
5 & Unweighted & 2,310 & 0.652 \\
5 & popdif*skilldif & 2,310 & 0.728 \\
10 & Unweighted & 10,395 & 0.606 \\
10 & popdif*skilldif & 10,395 & 0.688 \\
30 & Unweighted & 100,485 & 0.579 \\
30 & popdif*skilldif & 100,485 & 0.659 \\
90 & Unweighted & 925,155 & 0.561 \\
90 & popdif*skilldif & 925,155 & 0.634 \\
276 & Unweighted & $8,766,450$ & 0.533 \\
276 & popdif*skilldif & $8,766,450$ & 0.583 \\
\hline
\end{tabular}


Table 11: Industrial employment population elasticities

\begin{tabular}{|c|c|c|c|c|c|}
\hline$\beta_{\sigma_{1}}$ Apparel Manufacturing & 1.237 & 1.024 & $\beta_{\sigma_{11}}$ Nonmetallic Mineral Product Manufacturing & 1.018 & 0.955 \\
\hline$\times \log$ population & $(0.070)$ & $(0.148)$ & $\times \log$ population & $(0.036)$ & $(0.042)$ \\
\hline$\beta_{\sigma_{2}}$ Textile Product Mills & 1.125 & 0.905 & $\beta_{\sigma_{12}}$ Paper Manufacturing & 0.901 & 0.539 \\
\hline$\times \log$ population & $(0.056)$ & $(0.135)$ & $\times \log$ population & $(0.063)$ & $(0.104)$ \\
\hline$\beta_{\sigma_{3}}$ Leather and Allied Product Manufacturing & 0.743 & 0.147 & $\beta_{\sigma_{13}}$ Printing and Related Support Activities & 1.202 & 1.122 \\
\hline$\times \log$ population & $(0.099)$ & $(0.284)$ & $\times \log$ population & $(0.036)$ & $(0.047)$ \\
\hline$\beta_{\sigma_{4}}$ Furniture and Related Product Manufacturing & 1.120 & 1.000 & $\beta_{\sigma_{14}}$ Electrical Equipment, Appliance \& Component & 1.159 & 0.813 \\
\hline$\times \log$ population & $(0.050)$ & $(0.076)$ & $\times \log$ population & $(0.074)$ & $(0.111)$ \\
\hline$\beta_{\sigma_{5}}$ Textile Mills & 0.823 & 0.352 & $\beta_{\sigma_{15}}$ Machinery Manufacturing & 1.071 & 0.960 \\
\hline$\times \log$ population & $(0.105)$ & $(0.208)$ & $\times \log$ population & $(0.055)$ & $(0.069)$ \\
\hline$\beta_{\sigma_{6}}$ Wood Product Manufacturing & 0.848 & 0.608 & $\beta_{\sigma_{16}}$ Miscellaneous Manufacturing & 1.224 & 1.208 \\
\hline$\times \log$ population & $(0.055)$ & $(0.085)$ & $\times \log$ population & $(0.044)$ & $(0.059)$ \\
\hline$\beta_{\sigma_{7}}$ Fabricated Metal Product Manufacturing & 1.094 & 1.036 & $\beta_{\sigma_{17}}$ Beverage and Tobacco Product Manufacturing & 1.168 & 1.010 \\
\hline$\times \log$ population & $(0.048)$ & $(0.050)$ & $\times \log$ population & $(0.065)$ & $(0.147)$ \\
\hline$\beta_{\sigma_{8}}$ Food Manufacturing & 0.953 & 0.864 & $\beta_{\sigma_{18}}$ Transportation Equipment Manufacturing & 1.254 & 0.940 \\
\hline$\times \log$ population & $(0.050)$ & $(0.067)$ & $\times \log$ population & $(0.075)$ & $(0.101)$ \\
\hline$\beta_{\sigma_{9}}$ Plastics and Rubber Products Manufacturing & 1.105 & 0.975 & $\beta_{\sigma_{19}}$ Petroleum and Coal Products Manufacturing & 0.951 & 0.393 \\
\hline$\times \log$ population & $(0.056)$ & $(0.070)$ & $\times \log$ population & $(0.074)$ & $(0.308)$ \\
\hline$\beta_{\sigma_{10}}$ Primary Metal Manufacturing & 0.997 & 0.449 & $\beta_{\sigma_{20}}$ Computer and Electronic Product Manufacturing & 1.453 & 1.254 \\
\hline$\times \log$ population & $(0.078)$ & $(0.107)$ & $\times \log$ population & $(0.075)$ & $(0.108)$ \\
\hline & & & $\beta_{\sigma_{21}}$ Chemical Manufacturing & 1.325 & 0.992 \\
\hline & & & $\times \log$ population & $(0.065)$ & $(0.098)$ \\
\hline Observations & 5406 & 2130 & Observations & 5406 & 2130 \\
\hline R-squared & 0.564 & 0.541 & R-squared & 0.564 & 0.541 \\
\hline Industry FE & Yes & Yes & Industry FE & Yes & Yes \\
\hline Only uncensored obs & & Yes & Only uncensored obs & & Yes \\
\hline \multicolumn{6}{|c|}{ Standard errors, clustered by MSA, in parentheses } \\
\hline
\end{tabular}

Table 12: Pairwise comparisons of manufacturing industries

\begin{tabular}{|c|c|c|c|}
\hline Bins & Weights & Comparisons & Success rate \\
\hline 2 & Unweighted & 210 & .638 \\
2 & popdif*skilldif & 210 & .675 \\
3 & Unweighted & 630 & .640 \\
3 & popdif*skilldif & 630 & .665 \\
5 & Unweighted & 2,100 & .606 \\
5 & popdif*skilldif & 2,100 & .633 \\
10 & Unweighted & 9,450 & .561 \\
10 & popdif*skilldif & 9,450 & .597 \\
30 & Unweighted & 91,350 & .543 \\
30 & popdif*skilldif & 91,350 & .573 \\
90 & Unweighted & 841,050 & .522 \\
90 & popdif*skilldif & 841,050 & .549 \\
276 & Unweighted & $7,969,500$ & .495 \\
276 & popdif*skilldif & $7,969,500$ & .531 \\
\hline
\end{tabular}

Note: The number of cities per "bin" may differ by one, due to the integer constraint. 